\title{
Análise e projeto de múltiplas longarinas de uma ponte rodoviária utilizando concreto protendido
}

\author{
Analysis and design of multiple beams of a road bridge using prestressed concrete \\ Análisis y Diseño de vigas múltiples de un puente viales utilizando hormigón pretensado
}

Recebido: 08/02/2022 | Revisado: 16/02/2022 | Aceito: 18/02/2022 | Publicado: 26/02/2022

\author{
João Marcos da Silva \\ ORCID: https://orcid.org/0000-0003-0603-3631 \\ Universidade Federal de Pernambuco, Brasil \\ E-mail: joaomrcs12@hotmail.com \\ Douglas Mateus de Lima \\ ORCID: https://orcid.org/0000-0001-9279-0983 \\ Universidade Federal de Pernambuco, Brasil \\ E-mail: douglas.mlima@ufpe.br \\ Iálysson da Silva Medeiros \\ ORCID: https://orcid.org/0000-0001-7112-5984 \\ Universidade Federal de Pernambuco, Brasil \\ E-mail: ialysson.medeiros@ufpe.br \\ Matheus Alves Pereira \\ ORCID: https://orcid.org/0000-0001-6900-9415 \\ Universidade Federal de Pernambuco, Brasil \\ E-mail: matheus_alves1996@hotmail.com \\ Pablo Anníbal López-Yánez \\ ORCID: https://orcid.org/0000-0003-2285-1335 \\ Universidade Federal de Pernambuco, Brasil \\ E-mail: lopez.yanez@yahoo.com.br
}

\begin{abstract}
Resumo
No âmbito de projetos rodoviários, a construção de pontes representa um dos seus maiores custos. Assim, a busca de soluções economicamente mais viáveis que reduza o emprego de materiais e os aproveite de forma eficiente revela-se imprescindível. Nesse sentido, destaca-se a aplicação da protensão a tais estruturas, pois tal técnica permite explorar ao máximo a resistência à tração do aço e a resistência à compressão do concreto. Este trabalho consiste na elaboração de um projeto estrutural das múltiplas longarinas do tabuleiro de uma ponte utilizando concreto protendido. Os cálculos do projeto foram desenvolvidos no software Mathcad 15.0 - que, junto com softwares auxiliares, permitiu determinar os esforços atuantes em cada longarina do tabuleiro. Com tais valores, determinou-se a longarina mais solicitada, que foi dimensionada no restante do projeto. Posteriormente, determinou-se o esforço de protensão mínimo que deve atuar na estrutura. Em seguida, através do posicionamento do cabo equivalente de protensão, foram calculadas as perdas de protensão imediatas e progressivas. Ao final do projeto, foram verificadas as situações dos estados limites últimos de fadiga e de flexão da armadura ativa e também se realizou a verificação do estado limite de serviço de deformações excessivas. Os resultados obtidos permitiram concluir que a utilização da protensão contribuiu para reduzir a quantidade de aço utilizada na estrutura, além de diminuir as deformações e ainda melhorar o comportamento da viga aos efeitos da fadiga.
\end{abstract}

Palavras-chave: Concreto protendido; Pontes; Múltiplas longarinas.

\begin{abstract}
In the context of road projects, the construction of bridges represents one of the biggest costs. Thus, the search for more economically viable solutions that reduce the use of materials and use them efficiently is essential. In this sense, the application of prestressing to such structures stands out, because this technique allows the maximum exploitation of the tensile strength of steel and the compressive strength of concrete. This work consists in the elaboration of a structural project of the multiple beams of the deck of a bridge using prestressed concrete. The design calculation ware developed using Mathcad 15.0 software - which, together with auxiliary software, allowed determining the forces acting on each beam of the deck. With these values, the most requested beam was determined, which was dimensioned in the rest of the project. Subsequently, the minimum prestressing effort that must act on the structure was determined. Then, through the positioning of the equivalent prestressing cable, the immediate and progressive prestressing losses were calculated. At the end of the project, the situations of the ultimate fatigue and bending limit states of the active reinforcement were verified and the service limit state of excessive deformations was also verified. The results allowed to conclude that the
\end{abstract}


use of prestressing contributed to reduce the amount of steel used in the structure, besides reducing the deformations and also improving the behavior of the beam to the effects of fatigue.

Keywords: Prestressed concrete; Bridges; Multiple beams.

\section{Resumen}

En el contexto de proyectos viales, la construcción de puentes representa uno de los mayores costos. Por ello, la búsqueda de soluciones económicamente más viables que reduzcan el uso de materiales y los utilicen de manera eficiente es fundamental. En este sentido, destaca la aplicación del pretensado a este tipo de estructuras, ya que esta técnica permite aprovechar al máximo la resistencia a la tracción del acero y la resistencia a la compresión del hormigón. Este trabajo consiste en la elaboración de un proyecto estructural de las vigas múltiples del tablero de un puente utilizando hormigón pretensado. Los cálculos de diseño se desarrollaron utilizando el software Mathcad 15.0 - que, junto con un software auxiliar, permitió determinar las fuerzas que actúan sobre cada viga del tablero. Con estos valores se determinó el larguerillo más solicitado, el cual se dimensionó en el resto del proyecto. Posteriormente se determinó el esfuerzo mínimo de pretensado que debe actuar sobre la estructura. Luego, a través del posicionamiento del cable de pretensado equivalente, se calcularon las pérdidas de pretensado inmediatas y progresivas. Al final del proyecto se verificaron las situaciones de los estados límite de fatiga última y de flexión de la armadura activa y también se verificó el estado límite de servicio de deformaciones excesivas. Los resultados obtenidos permitieron concluir que el uso del pretensado contribuyó a reducir la cantidad de acero utilizado en la estructura, además de disminuir las deformaciones y también mejorar el comportamiento de la viga a los efectos de la fatiga.

Palabras clave: Hormigón pretensado; Puentes; Vigas múltiples.

\section{Introdução}

O aumento na demanda pelo transporte rodoviário de cargas e de passageiros é notável em virtude do crescimento urbano. Esse aumento implica na necessidade de mais veículos de grande porte em estradas, de um maior número de faixas por via e, em muitos casos, de pontes com vãos muito extensos. Essas pontes, do ponto de vista estrutural, precisam apresentar um sistema que lhes permitam resistir aos grandes esforços aplicados de maneira econômica, tendo em vista o custo elevado de suas construções.

Para as superestruturas dessas pontes com grandes carregamentos e vãos extensos, uma solução que possui excelentes vantagens é a utilização de múltiplas longarinas de concreto protendido. Esse sistema, ao ser comparado com as longarinas de concreto armado convencional, se torna mais interessante, pois, de acordo com Pfeil (1984), apresenta as seguintes vantagens: redução das quantidades necessárias de concreto e aço, devido ao emprego mais eficiente dos materiais; diminuição da altura necessária da viga para vencer longos vãos; redução da incidência de fissuras, garantindo maior durabilidade a peça; redução de tensões de tração provocadas pela flexão e pelos esforços cortantes.

A utilização do concreto protendido em pontes já é empregado em boa parte do Brasil, não sendo diferente na região Nordeste. Em Caruaru - PE, por exemplo, há quatro viadutos compostos por longarinas protendidas no trecho da BR 104 que intercepta o setor urbano da cidade. Os referidos viadutos foram construídos com o intuito de agilizar o trânsito na cidade. No entanto, para tal, foi necessário que se atravessasse quatro vias locais em cada elevação, o que corresponde a um vão de cerca de 65 m que foi dividido em dois vão vãos menores pela adição de um pilar central, resultando em dois tramos de vigas biapoiadas.

Caso tivesse sido utilizado concreto armado nas longarinas, que possuem cerca de $30 \mathrm{~m}$ de vão, seria necessário projetálas para uma altura de aproximadamente $3 \mathrm{~m}$, de acordo com a proporção de 10\% do vão para vigas biapoiadas. Por outro lado, com a utilização do concreto protendido, as longarinas aplicadas têm altura de apenas 1,7 m. Essa diferença apresenta-se como grande vantagem, pois, além de economizar material, as vigas com altura menor proporcionam uma altura livre maior para a passagem de veículos de grande porte sob o viaduto. Um dos viadutos, localizado na intersecção da Avenida Agamenon Magalhães com a BR 104, pode ser observado na Figura 1. 
Figura 1 - Viaduto com longarinas protendidas em Caruaru-PE.

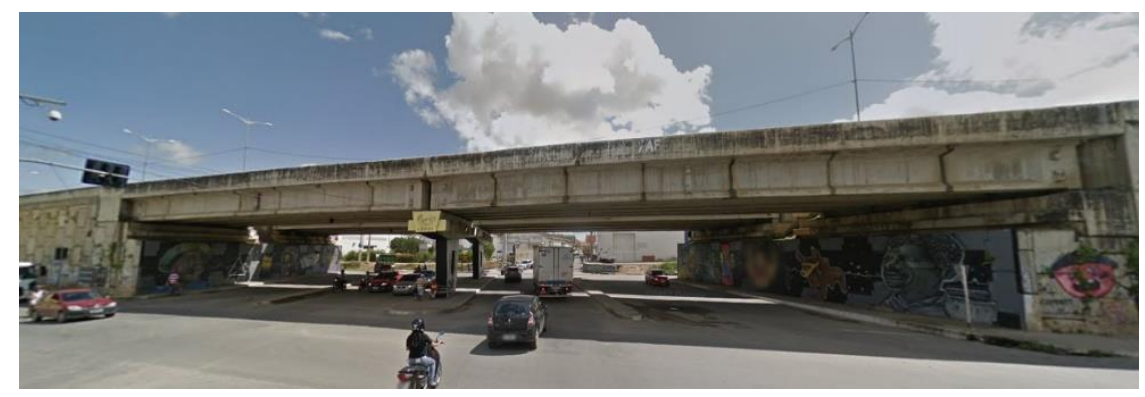

Fonte: Google Maps (2017).

O concreto protendido apresenta outra grande vantagem: a manutenção de suas características de comportamento após a atuação de um grande número de ciclos de carregamento (PFEIL, 1984). Tal propriedade é de grande relevância, especialmente, no que se diz respeito a pontes ferroviárias e rodoviárias. Portanto, as longarinas de concreto protendido apresentam um melhor comportamento no que se refere à fadiga da estrutura.

Além disso, com o aumento das larguras das pontes e viadutos, devido aos acréscimos de faixas, de acostamentos e também dos passeios, as cargas na superestrutura aumentaram consideravelmente. Para distribuir essas cargas de maneira que se trabalhem com seções transversais eficientes nas longarinas, utilizam-se várias das mesmas distribuídas paralelamente ao eixo da ponte. Nos viadutos supracitados, por exemplo, existem 5 longarinas por viaduto, como pode ser visto na Figura 2.

Figura 2 - Múltiplas longarinas em viaduto de Caruaru-PE.

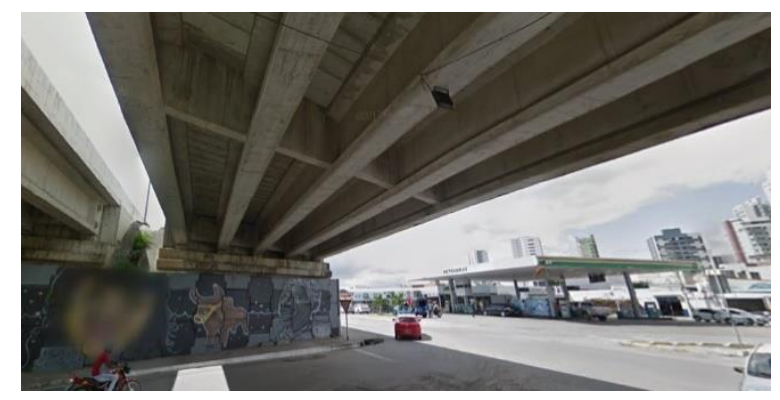

Fonte: Google Maps (2017).

A conexão entre as longarinas é realizada a partir das vigas transversinas, cujas funções são transmitir os esforços entre as vigas principais, contribuir para melhorar a rigidez à torção do tabuleiro e também aprimorar o seu contraventamento transversal. O sistema completo (longarina-transversina) apresenta um comportamento estrutural semelhante ao de uma grelha plana. Na Figura 2, observa-se uma transversina no viaduto.

As estruturas de pontes rodoviárias de concreto protendido, tem sido objeto de diversas análises realizadas por pesquisadores. Pode-se destacar os estudos realizados por Martí et al. (2013), Yepes et al. (2015), Martí et al. (2016), GarcíaSegura e Yepes (2016), García-Segura et al. (2017), Yepes et al. (2017), Penadés-Plà et al. (2017), Alcalá et al. (2018), PenadésPlà et al. (2018), Bonopera et al. (2019), Gonzalez-Vidosa et al. (2020), Silva et al. (2020), Hemalatha et al. (2021), e Nour et al. (2021).

Em vista disso e com intuito de explorar todas as vantagens apresentadas, de difundir ainda mais a utilização do concreto protendido na região e de aplicá-lo a uma situação real, o presente trabalho realizará a análise e o dimensionamento da longarina protendida apresentada na Figura 1 e na Figura 2 e também executará todas as verificações de estabilidade e segurança. Para isso, utilizam-se os métodos de Engesser-Courbon e Leonhardt para a distribuição transversal de cargas entre as vigas do 
tabuleiro da ponte e avaliar as diferenças nos resultados das linhas de influência e verificam-se os estados limites último e de serviço da estrutura de acordo com a ABNT NBR 6118 (2014).

\section{Metodologia}

O presente trabalho refere-se a uma análise cuja metodologia utilizada foi de natureza quali-quantitativa que permite uma investigação caracterizada pelo entendimento mais desenvolvido da realidade (Malhotra et al., 2005), com o propósito de apresentar teorias fundamentadas (Flick, 2009), sendo caracterizada pela utilização de dados numéricos, com medições de grandeza, em que se obtêm números com unidades que serão tratados matematicamente (Pereira et al., 2018).

\subsection{Descrição do Viaduto em estudo}

Como apresentado na Figura 3, o viaduto objeto desse trabalho é composto por dois trechos iguais de tabuleiros com vigas biapoiadas. A partir de levantamento realizado in loco pelo autor, obtiveram-se as dimensões do tabuleiro (Figura 3).

Figura 3 - Corte transversal do tabuleiro.

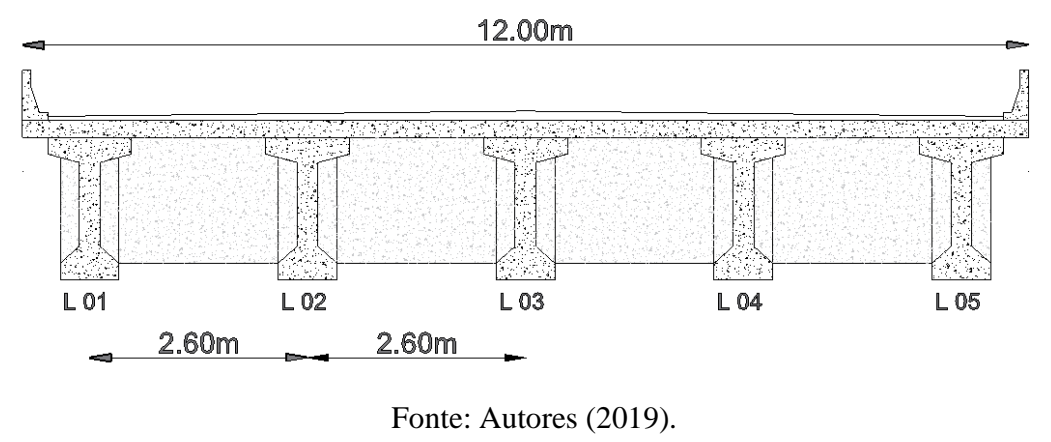

Observa-se que o viaduto possui uma largura total de $12 \mathrm{~m}$ e é composto por cinco longarinas igualmente espaçadas por uma distância de 2,60 m. Há guarda-corpos de concreto localizados nas extremidades laterais da pista e ainda um conjunto de três transversinas, sendo estas localizadas no centro e nas extremidades das vigas longitudinais. Na pista de rolamento, há ainda o revestimento asfáltico, com declividade de $2 \%$ para cada lado da via, que se apoia sobre uma laje de concreto armado com $20 \mathrm{~cm}$ de espessura.

No corte longitudinal (Figura 4), estão presentes o comprimento total das vigas (30 m) e o comprimento alargado nos apoios $(1 \mathrm{~m})$ para melhorar a resistência ao cisalhamento e alocar adequadamente as ancoragens dos cabos de protensão.

Figura 4 - Corte Longitudinal do Tabuleiro.

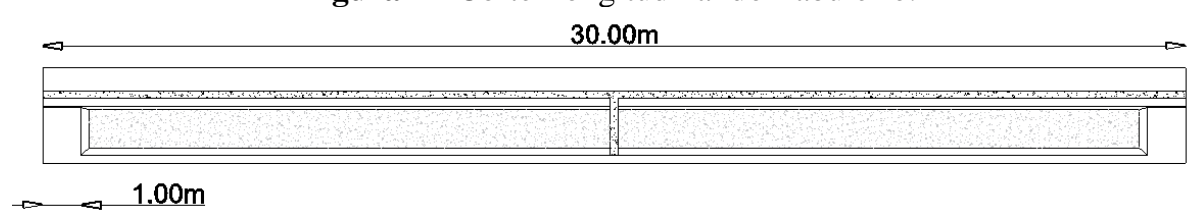

Fonte: Autores (2019).

As seções de controle foram então definidas, considerando um espaçamento de $2,5 \mathrm{~m}$, o que resultou em um total de 13 seções, como observado na Figura 5. Devido à simetria, toda a viga será dimensionada considerando as seções de 0 a 6 . 
Figura 5 - Seções de controle nas longarinas.

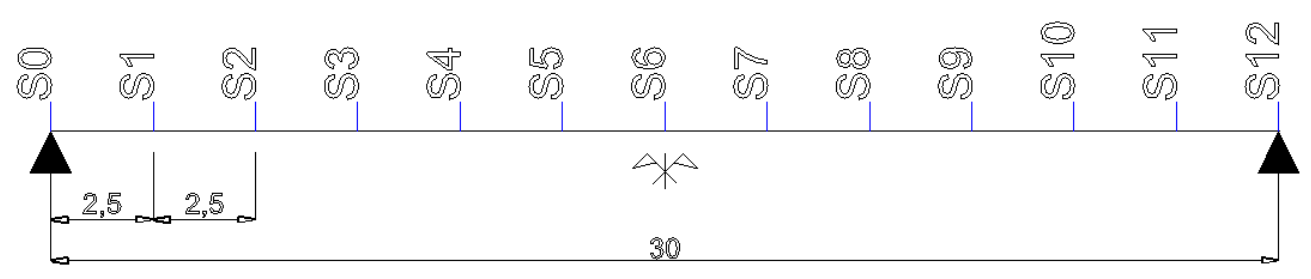

Fonte: Autores (2019).

A seção transversal das vigas ainda foi dividida em partes para facilitar o processo de obtenção das propriedades geométricas da mesma. A divisão pode ser observada na Figura 6 - em que estão representadas a geometria referente as seções de S1 a S11 e suas propriedades. As seções S0 e S12 são diferentes, pois possuem um alargamento para garantir maior resistência ao esforço cortante e mais espaço para alocar as ancoragens dos cabos de protensão.

Figura 6 - Seção transversal da longarina.

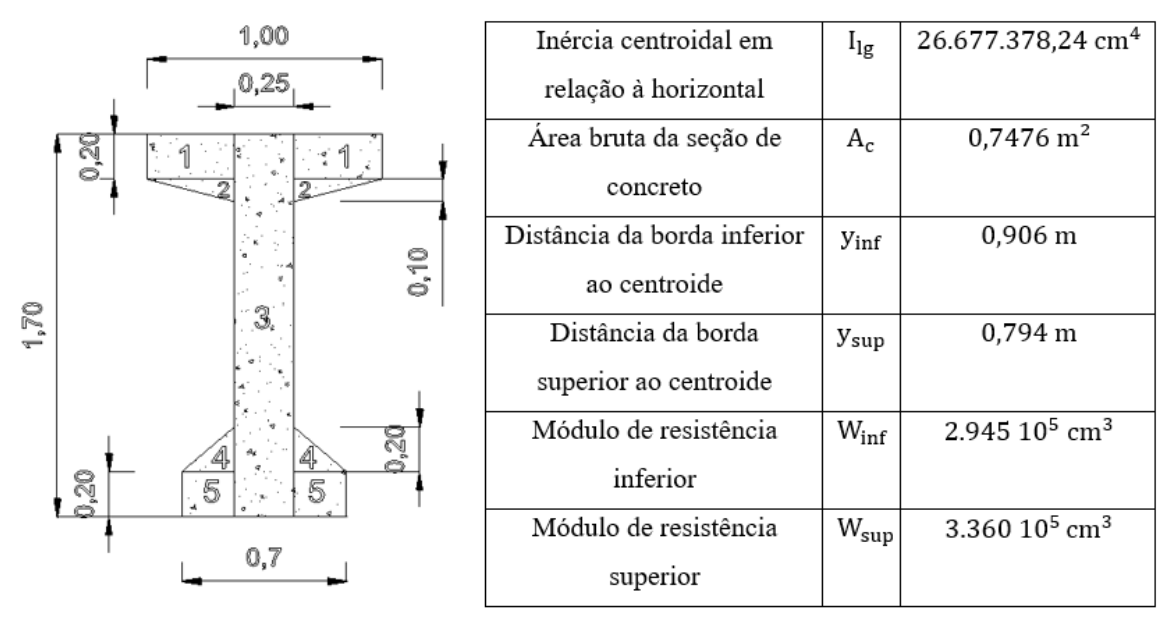

Fonte: Autores (2019).

\subsection{Materiais utilizados}

O presente projeto utilizará os materiais disponibilizados pela empresa Freyssinet, uma das maiores no ramo da protensão nacional e internacional. Dessa maneira, tanto as cordoalhas, quanto os cabos, ancoragens e os próprios macacos hidráulicos serão retirados do catálogo da empresa. No que diz respeito ao concreto, será utilizado o concreto com resistência característica à compressão de $35 \mathrm{MPa}$, por ser um valor correntemente empregado na região. Por fim, para as armaduras passivas da estrutura, será utilizado o aço CA-50.

\subsection{Linhas de Influência}

Para as três primeiras longarinas, pelo método de Engesser-Courbon, obtêm-se as linhas de influência da Figura 7a. Com o método de Leonhardt, obtêm-se as linhas de influência da Figura 7b, que apresentam um comportamento curvo com curvatura maior nas regiões próximas a longarina em análise, o que ocorre devido ao fato deste método considerar a rigidez do tabuleiro em função do momento de inércia das transversinas, diferentemente do método de Engesser-Courbon, que assume que essa rigidez é infinita. Por isso, o método de Leonhardt é utilizado no restante desse trabalho. 
Figura 7 - Linhas de influência.

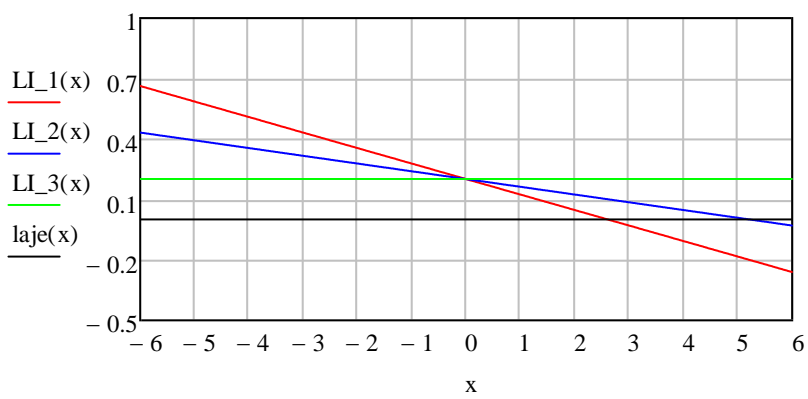

(a) Engesser-Courbon.

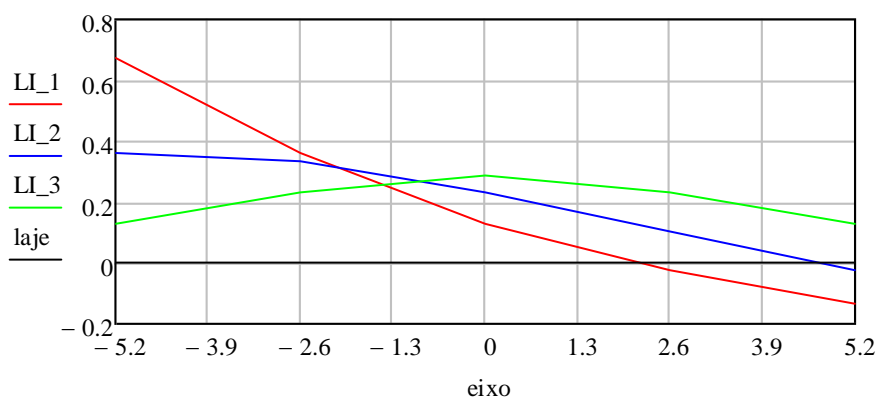

(b) Leonhardt.

Fonte: Autores (2019).

\subsection{Ações}

\subsubsection{Etapa 1 - Peso do Projeto}

Nessa etapa, em que será aplicado o esforço de protensão, o único carregamento atuante na viga é o peso próprio. Como todas as longarinas possuem a mesma geometria, a análise foi feita apenas uma vez. Iniciou-se pela determinação das cargas atuantes (Tabela 1). A longarina foi modelada em duas seções diferentes devido ao alargamento nas regiões dos apoios. Com as cargas obtidas, fez-se o lançamento da estrutura no Ftool (Figura 8).

Figura 8 - Carregamento da etapa 1.

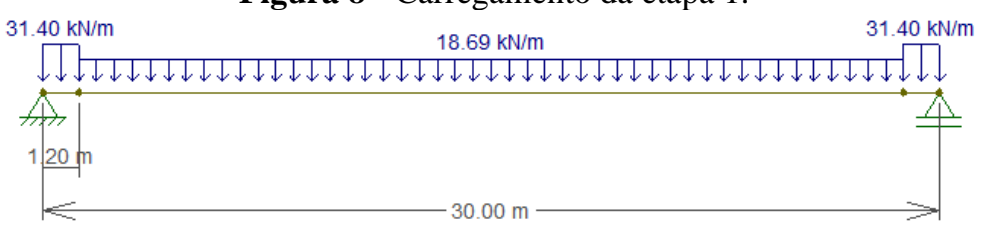

Fonte: Autores (2019).

\subsubsection{Etapa 2 - Transversinas e Laje}

Após se esperar 28 dias a partir da concretagem, as longarinas são protendidas e posteriormente posicionadas sobre os pilares. Em seguida, é realizada a concretagem das lajes e das transversinas, o que constitui a segunda etapa de carregamento permanente (Tabela 1).

Tabela 1 - Cargas.

\begin{tabular}{ccc|ccc}
\hline \multicolumn{2}{c|}{ Cargas permanentes da Etapa 1 } & \multicolumn{3}{c}{ Cargas dos elementos da Etapa 2 } \\
\hline \multirow{2}{*}{ Seção } & Área $\left(\mathrm{m}^{2}\right)$ & Carga $(\mathrm{kN} / \mathrm{m})$ & Laje & & \multicolumn{2}{c}{ Espessura $(\mathrm{m})$} & Carga $(\mathrm{kN} / \mathrm{m})$ \\
\cline { 5 - 6 } & 1,256 & 31,4 & \multirow{2}{*}{ Transversina } & Área $\left(\mathrm{m}^{2}\right)$ & Carga $(\mathrm{kN} / \mathrm{m})$ \\
\cline { 5 - 6 } & & 18,6875 & & 0,3 & 7,5 \\
\hline
\end{tabular}

Fonte: Autores (2019).

Nessa etapa de carregamento, as cargas transferidas para cada longarina são diferentes e para determiná-las, fez-se uma análise no Ftool de cada elemento agindo individualmente sobre a estrutura, de modo a descobrir a parcela do carregamento transferida a cada longarina. Na Figura 9, estão apresentados os carregamentos da laje e das transversinas. 
Figura 1 - Carregamento da laje e transversina (etapa 2).

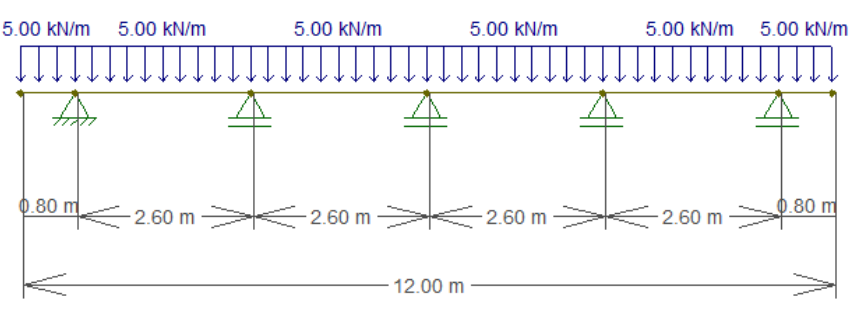

(a) Laje

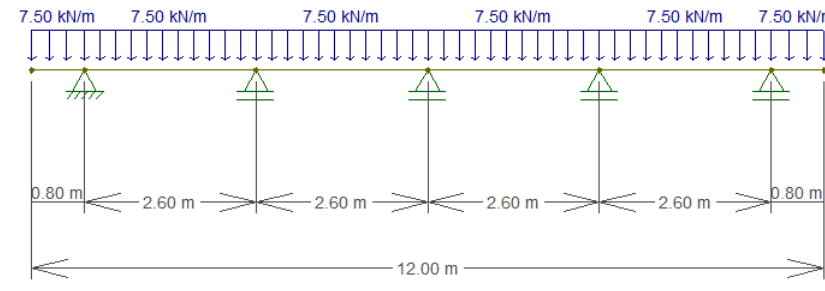

(b) Transversina

Fonte: Autores (2019).

Na figura acima, cada apoio representa uma longarina e as reações em cada uma representam os carregamentos aos quais estão submetidas. Os resultados retirados do Ftool podem ser observados na Tabela 2.

Tabela 2 - Cargas Permanentes - Etapa 2.

\begin{tabular}{cccccc}
\hline Longarina & L1 & L2 & L3 & L4 & L5 \\
\hline Reação da Laje $(\mathrm{kN} / \mathrm{m})$ & 13,2 & 12,5 & 13,2 & 12,5 & 13,2 \\
Reação da Transversina $(\mathrm{kN})$ & 14,8 & 20,7 & 18,9 & 20,7 & 14,8 \\
\hline
\end{tabular}

Fonte: Autores (2019).

Vale salientar que as cargas transferidas das lajes para as longarinas são lineares, enquanto que as das transversinas são cargas pontuais. Os carregamentos da Tabela 2 foram então lançados nas longarinas 1, 2 e 3, como pode ser visto na Figura 10.

Figura 2 - Carregamentos da etapa 2.

L1)

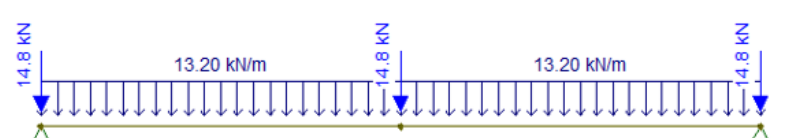

L2)
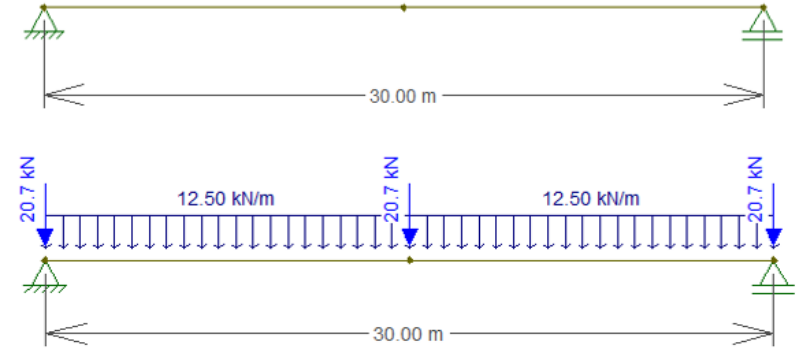

L3)

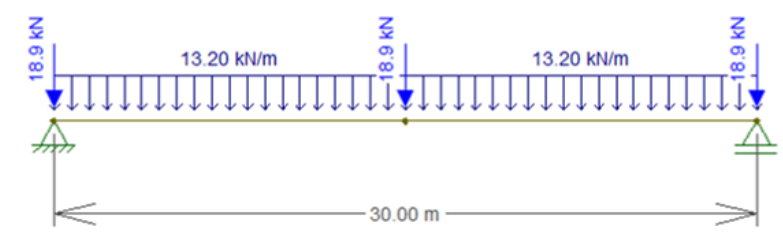

Fonte: Autores (2019).

Não foi necessária a consideração das longarinas 4 e 5, pois, por simetria, elas apresentam os mesmos comportamentos das longarinas 2 e 1 , respectivamente.

\subsubsection{Etapa 3 - Revestimento e Guarda-Corpos}

De acordo com Spernau (2012), nesse momento, devido as transversinas estarem concretadas, a transferência de cargas 
entre as longarinas começa a ser efetuada. Dessa forma, as distribuições das cargas dos últimos componentes a serem implantados no viaduto deve respeitar as linhas de influência apresentadas no item 2.3. Nessa etapa, o viaduto será finalizado com o posicionamento dos guarda-corpos e também com a aplicação do revestimento.

Na Figura 11, apresenta-se as cargas do revestimento e dos guarda-corpos que serão distribuídas entre as longarinas. As cargas dos guarda-corpos foram determinadas a partir de sua área e do peso específico do concreto, como já havia sido feito antes para os demais elementos do viaduto.

Figura 3 - Cargas do revestimento e dos guarda-corpos.

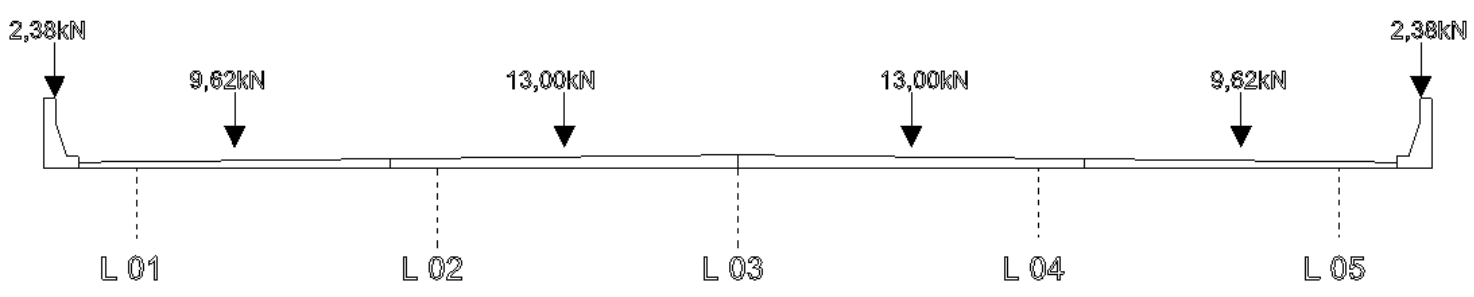

Fonte: Autores (2019).

Para o revestimento, no entanto, seguiu-se um procedimento diferente, pois a ABNT NBR 7187 (2003), além de fornecer o peso específico de $24 \mathrm{kN} / \mathrm{m}^{3}$ para o revestimento, recomenda a adição de $2 \mathrm{kN} / \mathrm{m}^{2}$, prevendo um futuro recapeamento. Assim, analisando um trecho de comprimento unitário do revestimento, fez-se a divisão da área do revestimento total em quatro parcelas. Duas delas referentes as vias principais da pista, cada uma com $3 \mathrm{~m}$ de largura, e duas referentes ao acostamento, com 2,70 m de largura cada. Com isso, montou-se a Tabela 3.

Tabela 3 - Cargas do Revestimento.

\begin{tabular}{cccccc}
\hline Via & Largura $(\mathbf{m})$ & Área $\left(\mathbf{m}^{2}\right)$ & Rev $(\mathbf{k N} / \mathbf{m})$ & Recap $(\mathbf{k N} / \mathbf{m})$ & Total $(\mathbf{k N} / \mathbf{m})$ \\
\hline Acostamento & 2,70 & 0,176 & 4,22 & 5,40 & 9,62 \\
Via Principal & 3,00 & 0,292 & 7,00 & 6,00 & 13,00 \\
\hline
\end{tabular}

\subsubsection{Etapa 4 - Cargas Móveis}

Foi utilizado no projeto o caso corrente do trem tipo TB-450, no qual a carga de multidão é de $5 \mathrm{kN} / \mathrm{m}^{2}$ e o veículo-tipo possui três eixos de duas rodas, espaçados a cada $1,5 \mathrm{~m}$, com $75 \mathrm{kN}$ em cada roda, conforme as prescrições da ABNT NBR 7188 (2013). Quanto aos coeficientes de ponderação, foi considerado o vão livre igual ao vão real de $30 \mathrm{~m}$ das vigas e o número de faixas igual a dois. Dessa forma, de acordo com a referida norma, o coeficiente de impacto vertical (CIV) e o coeficiente de número de faixas (CNF) obtidos foram: $\mathrm{CIV}=1,265$ e $\mathrm{CNF}=1,000$.

O coeficiente de impacto adicional (CIA) não foi considerado, pois não há descontinuidades da peça e também as longarinas não possuem trechos em balanço, de modo que apenas um trem-tipo por longarina será necessário para realizar a distribuição das cargas móveis. Assim, ao realizar a majoração pelos coeficientes CIV e CIA, os valores das cargas de multidão e da carga de roda passam a ser, respectivamente, $6,235 \mathrm{kN} / \mathrm{m}$ e $94,875 \mathrm{kN} / \mathrm{m}$.

Com os valores majorados, o veículo tipo foi então posicionado nas regiões mais críticas para cada uma das três longarinas, como pode ser observado na Figura 12. Em cada uma dessas figuras, estão apresentadas na parte inferior as linhas de influência da respectiva longarina, determinadas pelo método de Leonhardt, como visto no item 2.3. É importante observar que as cargas de multidão se propagam apenas nos trechos desfavoráveis das linhas de influência. 
Figura 4 - Veículo tipo sobre as longarinas.

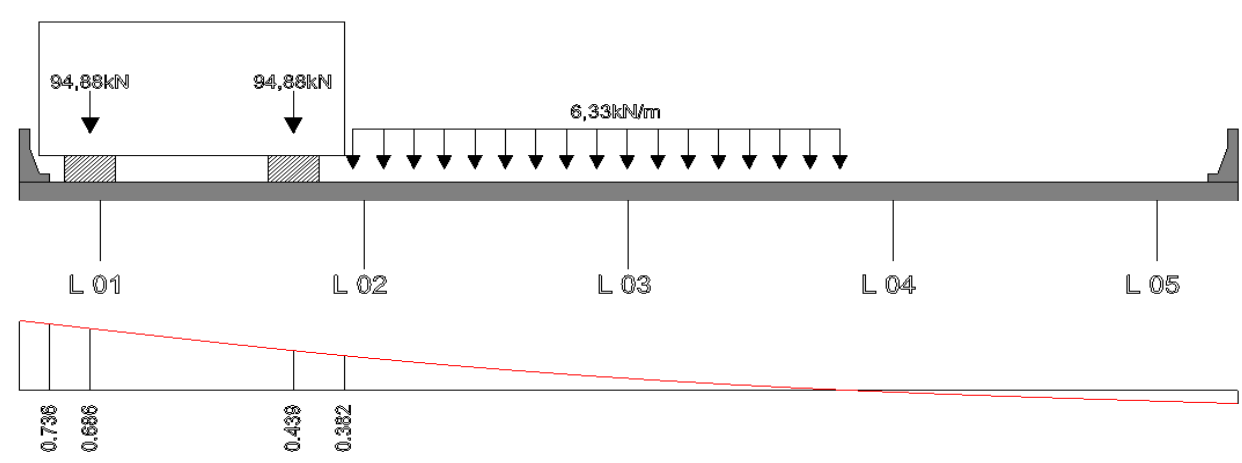

(a) Longarina 1 .

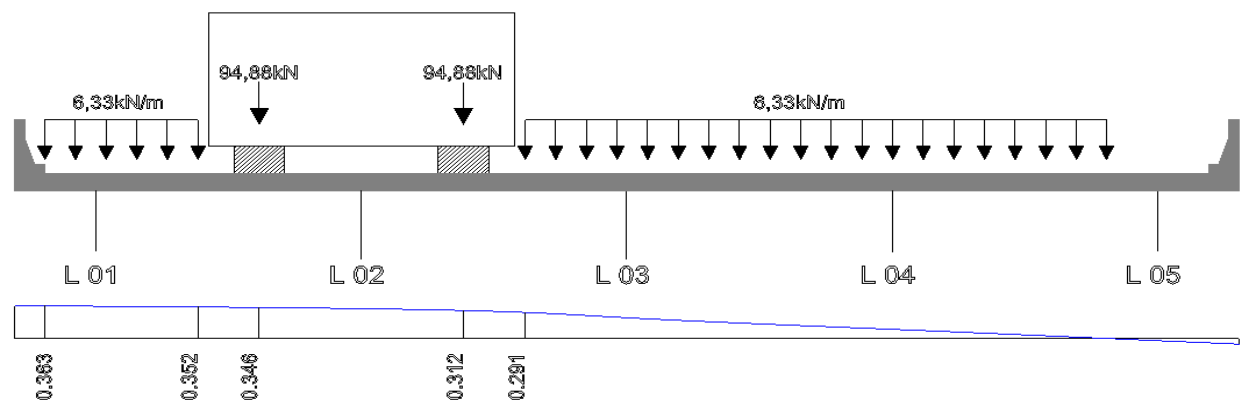

(b) Longarina 2 .

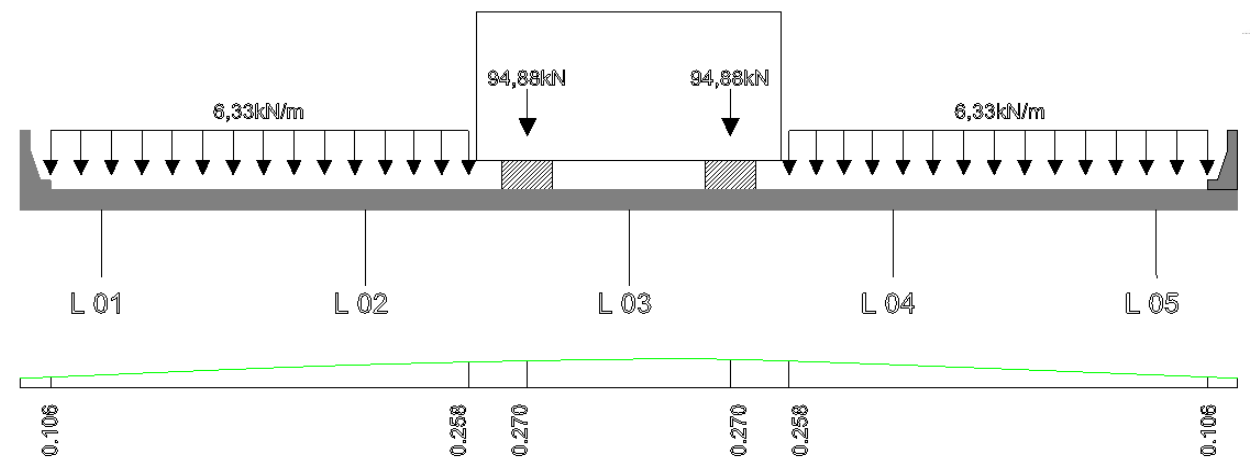

(c) Longarina 3 .

Fonte: Autores (2019).

\subsubsection{Distribuição Transversal das Cargas das Etapas 3 e 4}

Por atuarem na estrutura após a concretagem das transversinas, as cargas das etapas 3 e 4, apresentadas nos itens anteriores, precisam ser distribuídas de acordo com as linhas de influência de cada longarina. Para tal, as cargas são posicionadas sobre as linhas de influência e, com isso, são obtidas as cotas e áreas correspondentes. Por fim, foi realizada a multiplicação do esforço por sua parcela correspondente na linha de influência e foi obtido o quanto do esforço chega efetivamente na longarina em análise. Realizando o procedimento acima nas cargas da etapa 3, foi possível determinar o carregamento em cada longarina, como pode ser visto na Figura 5(a). Para a etapa 4, o mesmo procedimento é realizado, porém o resultado obtido para cada longarina é um trem-tipo, que podem ser observados na Figura 5(b). As combinações de ações forem feitas conforme a ABNT NBR 8681 (2003). 
Figura 5 - Distribuição Transversal das Cargas das Etapas 3 e 4.

L1)

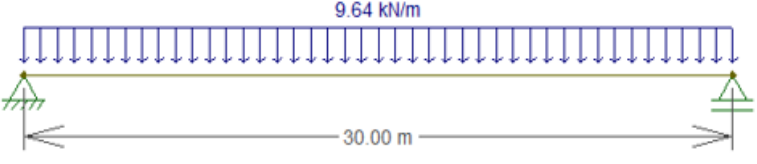

L2)

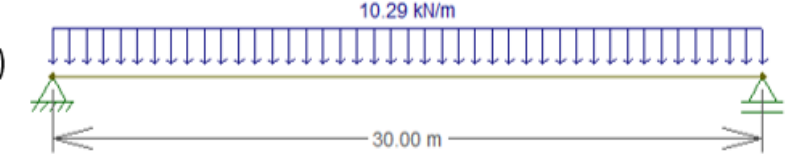

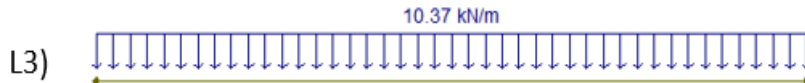

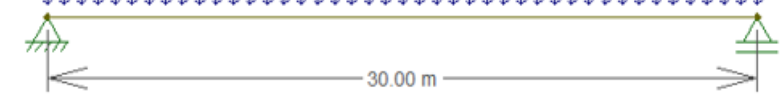

(a) Carregamentos da etapa 3.

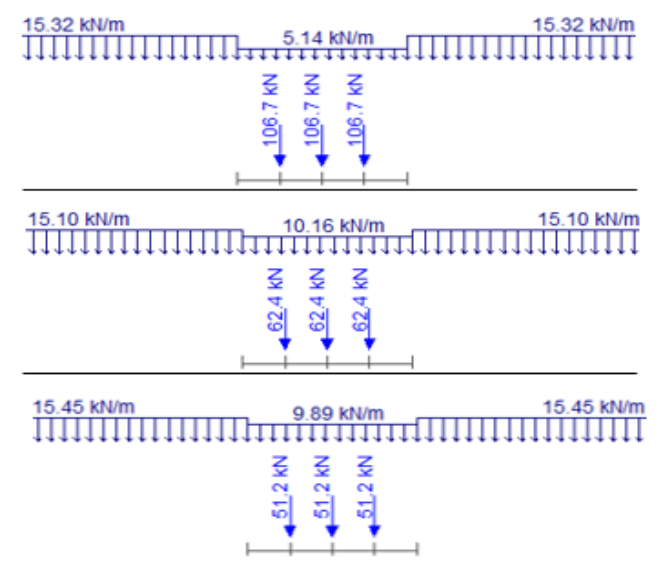

(b) Trem-tipo de cada longarina.

Fonte: Autores (2019).

\section{Resultados e Discussão}

\subsection{Determinação da Longarina de Projeto}

Com as seções definidas no item 2.1 e os carregamentos apresentados no item 2.4, foi possível determinar, a partir do Ftool, os momentos e esforços cortantes atuantes em cada seção para cada etapa de carregamento. A partir da combinação das quatro etapas de carregamento para cada longarina, concluiu-se que a longarina 1 é a que está submetida aos maiores esforços. Devido a isso, a mesma será utilizada para o dimensionamento e seus esforços podem ser observados na Tabela 4.

Tabela 4 - Esforços atuantes na longarina de projeto.

\begin{tabular}{c|cccc|cccc}
\hline \multirow{2}{*}{ Seção } & \multicolumn{3}{|c|}{ Momentos fletores (kN m) } & \multicolumn{4}{c}{ Esforços cortantes (kN) } \\
& ETAPA 01 & ETAPA 02 & ETAPA 03 & Móvel & ETAPA 01 & ETAPA 02 & ETAPA 03 & Móvel \\
\hline S0 & 0,0 & 0,0 & 0,0 & 0,0 & 295,6 & 205,4 & 144,6 & 491,5 \\
S1 & 651,8 & 472,2 & 331,4 & 1099,3 & 233,6 & 172,4 & 120,5 & 432,0 \\
S2 & 1117,3 & 862,0 & 602,5 & 1983,5 & 186,9 & 139,4 & 96,4 & 375,6 \\
S3 & 1586,1 & 1169,2 & 813,4 & 1663,9 & 140,2 & 106,4 & 72,3 & 322,4 \\
S4 & 1878,2 & 1394,0 & 964,0 & 3144,6 & 93,5 & 73,4 & 48,2 & 272,4 \\
S5 & 2053,4 & 1536,2 & 1054,4 & 3450,1 & 46,7 & 40,4 & 24,1 & 225,6 \\
S6 & 2111,8 & 1596,0 & 1084,5 & 3551,9 & 0,0 & 7,4 & 0,0 & 182,0 \\
\hline
\end{tabular}

Fonte: Autores (2019).

\subsection{Posicionamento dos cabos de Protensão}

Para se determinar a excentricidade máxima na seção mais crítica (S6), foram feitas algumas considerações. Considerando o viaduto sobre a classe de agressividade III, o cobrimento adotado foi de $4 \mathrm{~cm}$, de acordo com a Tabela 7.2 na ABNT NBR 6118 (2014). Também foi considerado um espaço para o posicionamento de estribos, que foram estimados com a bitola de $10 \mathrm{~mm}$. Considerou-se o espaço para o alojamento de uma camada de barras de armadura passiva com diâmetro de $20 \mathrm{~mm}$ e uma distância vertical entre essas barras e o cabo de protensão mais próximo de $20 \mathrm{~mm}$, conforme especificado no item 18.3.2.2 da ABNT NBR 6118 (2014). Ao total, resulta em uma distância de $9 \mathrm{~cm}$ entre as bordas da seção 6 e a face do cabo mais próximo.

Foi considerado inicialmente a utilização de 3 cabos, padrão Freyssinet, com diâmetro externo da bainha de $85 \mathrm{~mm}$ e o espaçamento vertical entre eles igual ao diâmetro, como recomenda-se na Tabela 18.1 da ABNT NBR 6118 (2014). A disposição 
dos três cabos e as demais dimensões supracitadas podem ser visualizadas na Figura 6. Porém, vale salientar que todo o dimensionamento será realizado utilizando o cabo equivalente aos três, que fica posicionado no centroide dos cabos.

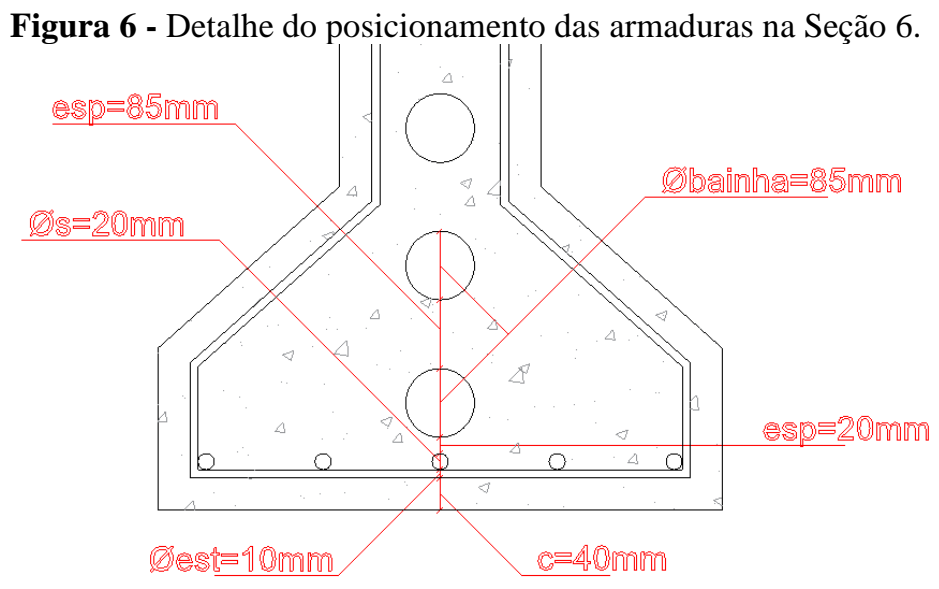

Fonte: Autores (2019).

Assim, considerando a distância do bordo inferior até o centroide da seção $\left(\mathrm{y}_{\text {inf }}\right)$ e as distâncias apresentadas na Figura 6, a excentricidade máxima do cabo equivalente $\left(\mathrm{e}_{\mathrm{p}}\right)$ pode ser determinada pela seguinte Equação 1 :

$$
\mathrm{e}_{\mathrm{p}}=\mathrm{y}_{\mathrm{inf}}-9 \mathrm{~cm}-2,5 \emptyset_{\text {bainha }}=90,60 \mathrm{~cm}-9 \mathrm{~cm}-2,5 \cdot 8,5 \mathrm{~cm}=60,35 \mathrm{~cm}
$$

\subsection{Determinação do Esforço de Protensão}

\subsubsection{Verificação quanto à protensão completa}

Por se tratar da situação na qual não surgem tensões de tração na seção, verificou-se a possibilidade de utilizar esse tipo de protensão no projeto. Determinou-se o esforço mínimo de protensão suficiente para anular todas as tensões de tração na seção. Utilizou-se a combinação rara de momentos, por se tratar da mais crítica nessa situação.

Para determinar o esforço necessário, foram levados em consideração todas as etapas de carregamento, visto que o esforço de protensão deve ser dimensionado para o tempo infinito. Por outro lado, no momento de aplicação do esforço, quando só está atuando o peso próprio da estrutura, a tensão de compressão causada pelo esforço de protensão não pode ser maior que $60 \%$ da resistência característica do concreto (PFEIL, 1980).

Assim, calculou-se a protensão duas vezes: a primeira com todos os momentos atuando para determinar o esforço mínimo necessário $\left(\mathrm{P}_{\text {nec }}\right)$; a segunda com apenas o peso próprio atuando para determinar o esforço máximo $\left(\mathrm{P}_{\text {máx }}\right)$ possível na peça sem que ela rompa por compressão excessiva. Os valores obtidos estão apresentados na Tabela 5.

Tabela 5 - Esforços calculados para protensão completa.

\begin{tabular}{cc}
\hline $\mathbf{P}_{\text {nec }}$ & $8.36610^{3} \mathrm{kN}$ \\
\hline $\mathbf{P}_{\text {máx }}$ & $8.31710^{3} \mathrm{kN}$ \\
\hline
\end{tabular}

Fonte: Autores (2019).

Como mostrado na Tabela 5, o esforço de protensão necessário $\left(\mathrm{P}_{\text {nec }}\right)$ para poder ser considerado a situação de protensão completa resultou num valor maior que o esforço máximo permitido $\left(\mathrm{P}_{\text {máx }}\right)$. Dessa maneira, não foi possível considerar a protensão completa e partiu-se então para a protensão limitada. 


\subsubsection{Protensão Limitada}

Para a protensão limitada, as combinações em serviço utilizadas são as combinações frequente e quase-permanente, cujos valores dos coeficientes de redução das ações variáveis, de acordo com a ABNT NBR 8681 (2003), são $\Psi_{1}=0,5$ e $\Psi_{2}=0,3$, respectivamente. Na protensão limitada, a combinação frequente deve satisfazer o estado limite de formação de fissuras, não podendo haver tensões de tração superiores a $f_{\text {ctkinf }}$ em nenhum ponto da seção. Já a combinação quase-permanente deve respeitar o estado limite de descompressão, não podendo haver qualquer tensão de tração.

Com essas considerações, foram determinados os esforços mínimos e máximos de protensão analisando as fibras superiores e inferiores da seção mais crítica do projeto (S6). Foi realizado o mesmo procedimento apresentado anteriormente, no entanto, agora foram introduzidos os coeficientes de minoração dos esforços variáveis e as tensões limites foram adaptadas para cada tipo de combinação. Os resultados estão apresentados na Tabela 6.

Tabela 6 - Valores mínimos e máximos de protensão.

\begin{tabular}{cccc}
\hline COMBINAÇÃO & FIBRA ANALISADA & \multicolumn{2}{c}{ ESFORÇO $(\mathbf{k N})$} \\
\hline \multirow{3}{*}{ Frequente } & \multirow{2}{*}{ Superior } & máx & 18610 \\
& & mín & -3164 \\
\cline { 2 - 4 } & \multirow{2}{*}{ Inferior } & máx & 8317 \\
& & mín & 5992 \\
\hline \multirow{2}{*}{ Quase-Permanente } & \multirow{2}{*}{ Superior } & máx & 18610 \\
& & mín & -7774 \\
\cline { 2 - 4 } & \multirow{2}{*}{ Inferior } & máx & 8317 \\
& & mín & 5873 \\
\hline
\end{tabular}

Fonte: Autores (2019).

Assim, com o intuito de dimensionar as longarinas de maneira econômica, foi selecionado o menor esforço possível que atenda a todos os intervalos apresentados na Tabela 6. Dessa maneira, o esforço de protensão do projeto no tempo infinito será $P_{\text {inf }}=5992 \mathrm{kN}$.

\subsection{Pilares}

A ABNT NBR 7483 (2008) classifica as cordoalhas de acordo com o número de fios, sendo estes 3 ou 7 fios, e pela resistência a tração do aço, sendo ela $190 \mathrm{kN} / \mathrm{mm}^{2}$ ou $210 \mathrm{kN} / \mathrm{mm}^{2}$. Para o presente trabalho, foi selecionada a cordoalha de 7 fios do aço CP 190 RB, cuja resistência caraterística a tração última é igual a $\mathrm{f}_{\text {ptk }}=1900 \mathrm{MPa}$. Já a resistência característica ao escoamento dessa cordoalha será dada pela Equação 2, visto que se trata de um aço com relaxação baixa, dessa forma tem-se:

$$
\mathrm{f}_{\text {pyk }}=0,9 \mathrm{f}_{\mathrm{ptk}}=1710 \mathrm{MPa}
$$

A área da cordoalha selecionada, de acordo com a ABNT NBR 7483 (2008), é igual a $A_{\text {cord }}=143 \mathrm{~mm}^{2}$. De acordo com o item 9.6.1.2.1 da ABNT NBR 6118 (2014), a tensão inicial na armadura de protensão $\left(\sigma_{\mathrm{pi}}\right)$ deve ser o menor valor entre $0,74 f_{p t k}$ e $0,82 f_{\text {pyk }}$, assim tem-se como resultado a Equação 3 :

$$
\sigma_{\mathrm{pi}} \leq\left\{\begin{array}{l}
0,74 \mathrm{f}_{\mathrm{ptk}}=0,74 \cdot 1900 \mathrm{MPa} \\
0,82 \mathrm{f}_{\mathrm{pyk}}=0,82 \cdot 1710 \mathrm{MPa}
\end{array} \rightarrow \sigma_{\mathrm{pi}}=1402 \mathrm{MPa}\right.
$$

De posse da área de uma cordoalha e da tensão inicial que ela suporta, pode-se determinar a força inicial $\left(\mathrm{p}_{\mathrm{i}}\right)$ suportada por cada cordoalha, como é visto na Equação 4: 


$$
\mathrm{p}_{\mathrm{i}}=\mathrm{A}_{\mathrm{cord}} \cdot \sigma_{\mathrm{pi}}=200,515 \mathrm{kN}
$$

Para determinar o número total de cordoalhas do projeto, é necessário conhecer o esforço resistido por cada cordoalha no tempo infinito. Para isso, como ainda não se tem dados das perdas de protensão, faz-se uma estimativa inicial de $30 \%$ de perdas totais. Dessa maneira o esforço que cada cordoalha resiste no tempo infinito é dado pela Equação 5.

$$
\mathrm{p}_{\text {cord_inf }}=70 \% \mathrm{p}_{\mathrm{i}}=140,36 \mathrm{kN} / \text { cord }
$$

Assim, o número de cordoalhas necessário para suportar o esforço total, apresentado no item 4.3.3 é obtido pela Equação 6:

$$
\mathrm{n}_{\text {cord }}=\frac{\mathrm{P}_{\text {inf }}}{\mathrm{p}_{\text {cord_inf }}}=42 \text { cordoalhas }
$$

Estudando o catálogo Freyssinet Brasil (2018), encontrou-se como melhor solução a utilização de 3 cabos de 85 mm de diâmetro com 15 cordoalhas cada, totalizando 45 cordoalhas ao total. Como a estimativa inicial para a determinação da excentricidade máxima considerou essa configuração de cabos, nada precisará ser alterado.

\subsection{Traçado do cabo equivalente}

A parábola de segundo grau é a curva ideal para representar os trechos curvos do cabo para cargas uniformemente distribuídas. No presente trabalho, será considerado todo o cabo como curvo, sem a presença de trechos retos, de maneira a avaliar melhor como as perdas variam em função da curvatura do mesmo. Assim, partindo do centroide das seções transversais nas extremidades da viga e chegando ao meio da viga com a excentricidade máxima encontrada no item 3.2, foi realizado o traçado do cabo equivale, que pode ser visualizado na Figura 7.

Figura 7 - Traçado do cabo equivalente.

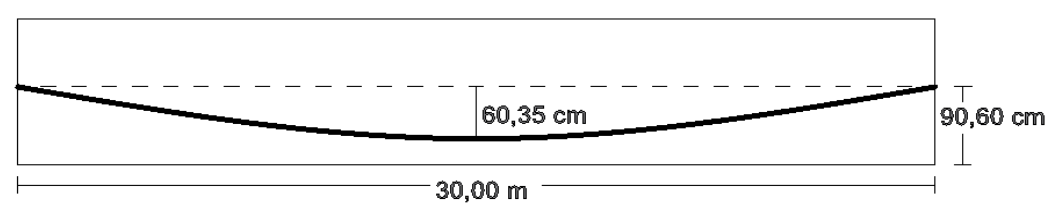

Fonte: Autores (2019).

Para determinar a equação da parábola apresentada acima, fez-se o uso dos pontos onde se conhecem a coordenada $x$, que representa o comprimento da longarina, a excentricidade $e(x)$ e a sua derivada que representa a inclinação do cabo $\alpha(x)$. Para isso, basta determinar os coeficientes $a, b$ e $c$ da Equação 7 .

$$
\mathrm{e}(\mathrm{x})=a \mathrm{x}^{2}+\mathrm{bx}+\mathrm{c}
$$

a partir da qual, através de sua primeira derivada, se obtêm a Equação 8.

$$
\alpha(x)=2 a x+b
$$


As informações conhecidas são que para $x=0 \mathrm{~m}$, tem-se que $e(x=0)=0 \mathrm{~cm}$, para $x=15 \mathrm{~m}$, tem-se que $e(x=15)=60,35 \mathrm{~cm}$, valor da excentricidade máxima, e $\alpha(x=15)=0 \mathrm{rad}$, ponto onde a inclinação muda. Resolvendo o sistema com essas três considerações, são encontrados os coeficientes $a, b$ e $c$. As equações finais são apresentadas são apresentadas a seguir:

$$
\begin{gathered}
e(x)=-2,682 \cdot 10^{-3} x^{2}+0,08 x \\
\alpha(x)=-5,364 \cdot 10^{-3} x+0,08
\end{gathered}
$$

Fazendo o uso das Equações acima, é possível conhecer a excentricidade e a inclinação de cada seção de controle da viga. Com as excentricidades determinadas, junto com os momentos apresentados para cada seção na Tabela 7, foi novamente efetuado o procedimento do item 3.3.3 para determinar os valores de protensão mínimos e máximos de cada seção. Para realizar essa determinação, utilizou-se diretamente a combinação frequente, pois ela apresenta os maiores valores mínimos. Os resultados obtidos podem ser observados na Tabela abaixo.

Tabela 7 - Valores máximos e mínimos de protensão para cada seção.

\begin{tabular}{ccc}
\hline SEÇão & ESFORÇO MÁX $(\mathbf{k N})$ & ESFORÇO MíN $(\mathbf{k N})$ \\
\hline S0 & 15390 & -1646 \\
S1 & 11820 & 2323 \\
S2 & 10010 & 3994 \\
S3 & 9179 & 5008 \\
S4 & 8666 & 5532 \\
S5 & 8400 & 5829 \\
S6 & 8317 & 5992 \\
\hline
\end{tabular}

Fonte: Autores (2019).

Os valores apresentados na Tabela acima serão importantes para os próximos itens pois será necessário avaliar se, após as perdas de protensão, os esforços no cabo atenderão os limites mínimos e máximos em cada seção.

\subsection{Cálculo das perdas efetivas de protensão}

Para se determinar as perdas efetivas, deve-se conhecer primeiramente o esforço inicial que será aplicado aos cabos. Como se conhece apenas o esforço no tempo infinito, deve-se realizar uma estimativa das perdas para que se possa determinar o esforço inicial. Assim, considerando mais uma vez o valor de $30 \%$ de perdas, tem-se que o esforço de protensão inicial total $\left(\mathrm{P}_{\mathrm{i}}\right)$ é obtido com a Equação 10:

$$
\mathrm{P}_{\mathrm{i}}=\frac{\mathrm{P}_{\mathrm{inf}}}{0,70}=8492 \mathrm{kN}
$$

Por se tratarem de três cabos, tem-se que o esforço de protensão inicial por cabo $\left(P_{i_{-} c a b o}\right)$ é dado pela Equação 11:

$$
\mathrm{P}_{\mathrm{i} \_ \text {cabo }}=\frac{\mathrm{P}_{\mathrm{i}}}{3}=2831 \mathrm{kN}
$$




\subsubsection{Perdas imediatas}

(a) Compensação de perdas no sistema de protensão

Para compensar as perdas por atrito no macaco hidráulico, deve-se realizar um acréscimo de 5\% na tensão aplicada. O macaco selecionado para esse projeto foi o Modelo Freyssinet K-350, pois o esforço máximo que ele suporta é de $3370 \mathrm{kN}$, sendo o primeiro no catálogo da empresa a suportar o esforço $\mathrm{P}_{\mathrm{i}}$ cabo. Ainda segundo o catálogo, a área do cilindro desse macaco é $\mathrm{A}_{\text {cil }}=498 \mathrm{~cm}^{2}$.

É necessário conhecer a tensão máxima a ser aplicada no cabo $\left(\sigma_{\text {p_máx }}\right)$, determinada pela Equação 13 que corresponde a divisão do esforço de protensão inicial no cabo $\left(\mathrm{P}_{\mathrm{i}_{-} \text {cabo }}\right)$ pela área do cabo $\left(\mathrm{A}_{\mathrm{p}_{-} \text {cabo }}\right)$, essa que por sua vez diz respeito a área de 15 cordoalhas, como está determinado na Equação 12.

$$
\begin{aligned}
\mathrm{A}_{\mathrm{p}_{\_} \text {cabo }} & =15 \mathrm{~A}_{\text {cord }}=21,45 \mathrm{~cm}^{2} \\
\sigma_{\mathrm{p}_{\text {_máx }}} & =\frac{\mathrm{P}_{\mathrm{i} \_ \text {cabo }}}{\mathrm{A}_{\mathrm{p} \_ \text {cabo }}}=1320 \mathrm{MPa}
\end{aligned}
$$

Portanto, o resultado da tensão a ser aplicada no macaco $\left(p_{\text {macaco }}\right)$ está apresentado na Equação 14:

$$
\mathrm{p}_{\text {macaco }}=1,05 \frac{\sigma_{\mathrm{p}_{\text {máx }}} A_{\mathrm{p}_{\text {cabo }}}}{\mathrm{A}_{\text {cil }}}=59,685 \mathrm{MPa}
$$

Como a tensão máxima que o macaco K-350 suporta é de 69 MPa não há necessidade de selecionar um macaco diferente.

(b) Perdas por atrito ao longo do cabo

O coeficiente de atrito entre o cabo e a bainha metálica informado no catálogo Freyssinet Brasil (2018) é $\mu=0,24$, enquanto que o coeficiente de atrito por unidade de comprimento é $\mathrm{k}_{0}=0,001$. A partir de $\mu$ e $\mathrm{k}_{0}$, determina-se a variação angular por metro linear do cabo (k), utilizando a Equação 19, como se pode observar na Equação 60 :

$$
\mathrm{k}=\frac{\mathrm{k}_{0}}{\mu}=4,167 \cdot 10^{-3}
$$

(c) Perdas por encunhamento

A acomodação da ancoragem Freyssinet para as cordoalhas de diâmetro nominal de 15,2 mm provoca uma penetração média de $6 \mathrm{~mm}$ durante a cravação das mesmas. Com esse valor de penetração, foi efetuado o cálculo para descobrir o comprimento de propagação das perdas por encunhamento e constatou-se que esse comprimento foi maior que a metade do vão. Assim, determinou-se o novo esforço de protensão na seção 0 e em seguida determinou-se as demais perdas nas outras seções (Tabela 8).

(d) Perdas por encurtamento elástico

Ao se efetuar o cálculo da razão entre os módulos de elasticidade da armadura ativa e do concreto obteve-se a relação $\alpha_{\mathrm{p}}=6,802$ e, como foi determinado previamente o número de cabos do projeto é igual a três $(\mathrm{n}=3)$. Associando essas 
informações com as demais já apresentadas, foi possível determinar as perdas por encurtamento para cada seção de controle a partir da Equação 22.

Vale ressaltar que para a utilização dessa equação, o esforço de protensão aplicado já considera as perdas por atrito e por ancoragem. Os resultados obtidos podem ser consultados na Tabela 8.

As três perdas imediatas calculadas estão apresentadas na Tabela 8. Como pode ser observado na figura, as perdas por atrito diminuem a cada seção, o que é explicado pelo fato de a trajetória do cabo sair com inclinação máxima na extremidade e chegar na inclinação zero no centro da viga. No entanto, em nenhum momento ela é zerada pois ainda conta com o atrito por unidade linear do cabo. A perda por ancoragem apresenta um aumento ao longo das seções visto que a mesma varia com o comprimento do cabo. Já a perda por encurtamento foi a que apresentou a maior variação, o que é explicado pelo fato dela depender dos momentos das seções, que aumentam à medida que se aproxima da seção central.

Tabela 8 - Perdas.

\begin{tabular}{cccc}
\hline SEÇÃO & $\begin{array}{c}\text { PERDAS POR } \\
\text { ATRITO }(\mathbf{k N})\end{array}$ & $\begin{array}{c}\text { PERDAS POR } \\
\text { ECUNHAMENTO }(\mathbf{k N})\end{array}$ & $\begin{array}{c}\text { PERDAS POR ENC. } \\
\text { ELÁSTICO }(\mathbf{k N})\end{array}$ \\
\hline S0 & 162,19 & 201,141 & 158,677 \\
S1 & 156,44 & 212,502 & 180,221 \\
S2 & 150,45 & 224,335 & 228,820 \\
S3 & 144,45 & 236,169 & 288,465 \\
S4 & 138,45 & 248,003 & 340,880 \\
S5 & 132,45 & 259,836 & 376,487 \\
S6 & 126,44 & 271,670 & 388,907 \\
\hline
\end{tabular}

Fonte: Autores (2019).

As três perdas imediatas foram então descontadas do esforço de protensão inicial $\left(\mathrm{P}_{\mathrm{i}}\right)$ e obteve-se o esforço imediatamente após a protensão $\left(\mathrm{P}_{0}\right)$ em cada uma das seções. Esse último esforço pode ser observado na Figura 9 . Nela é possível perceber que o esforço de protensão efetivo é reduzido a cada seção da viga, no entanto, é necessário que ele se mantenha dentro dos limites de cada seção, o que pode ser verificado na Figura 9. Nesta figura, observa-se que o esforço $\mathrm{P}_{0}$ encontra-se em todos momentos dentro da região delimitada pelos esforços máximos e mínimos. Dessa maneira, não há necessidade de alterações. 
Figura 8 - Perdas imediatas efetivas e esforço de protensão após as perdas imediatas.

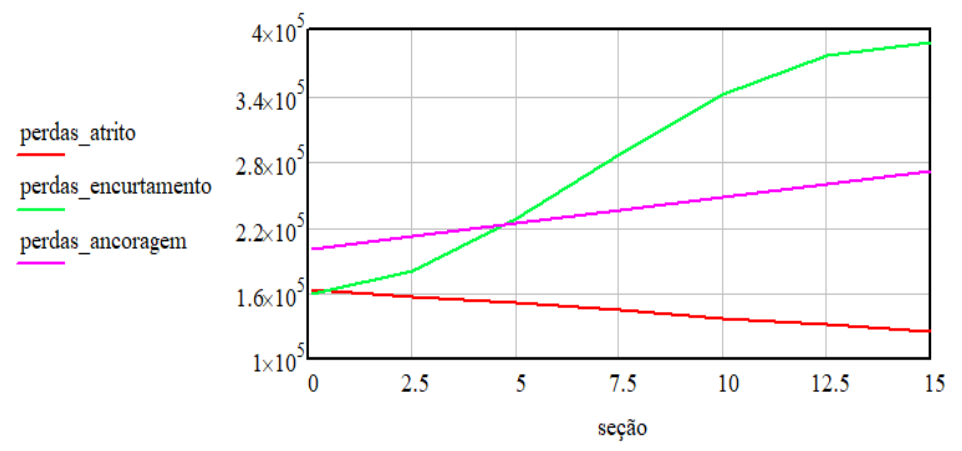

(a) Perdas imediatas efetivas $(\mathrm{N})$.

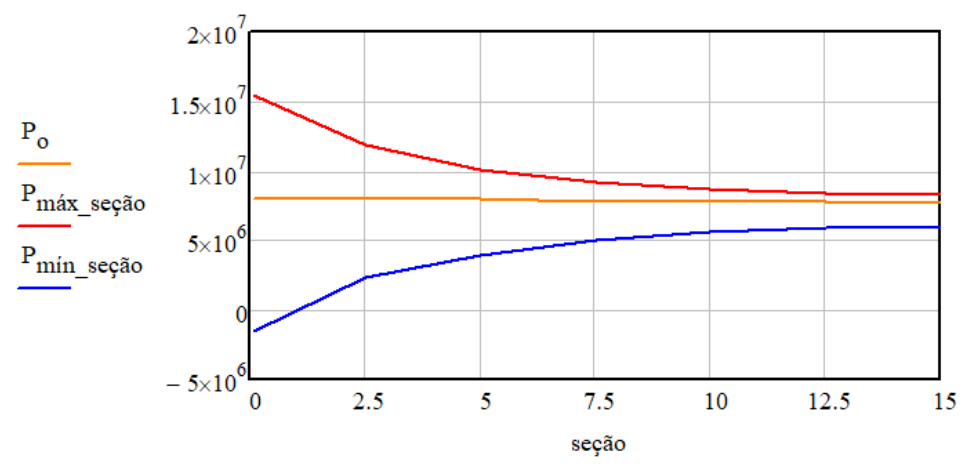

(b) Protensão após as perdas imediatas (N).

Fonte: Autores (2019).

\subsubsection{Perdas progressivas}

Para o presente projeto foi considerado a utilização do cimento CP V-ARI devido sua capacidade de atingir resistências altas em pouco tempo após a concretagem. Para os cálculos referentes a retração e fluência do concreto foram feitas as seguintes considerações: slump de $9 \mathrm{~cm}$; umidade relativa média do de $60 \%$; temperatura média de $25^{\circ} \mathrm{C}$; idade de aplicação da protensão de 28 dias; idade correspondente ao tempo infinito de 1000 dias. Com esses dados, calcularam-se as perdas progressivas (Tabela 9).

Tabela 9 - Perdas progressivas efetivas e Esforço efetivo de protensão em cada seção.

\begin{tabular}{ccc}
\hline SEÇÃO & PERDAS PROGRESSIVAS $(\mathbf{k N})$ & ESFORÇO EFETIVO FINAL $(\mathbf{k N})$ \\
\hline S0 & 1303 & 6.668 \\
S1 & 1347 & 6.596 \\
S2 & 1456 & 6.433 \\
S3 & 1573 & 6.251 \\
S4 & 1682 & 6.083 \\
S5 & 1757 & 5.967 \\
S6 & 1783 & 5.922 \\
\hline
\end{tabular}

Fonte: Autores (2019).

Através da subtração do esforço $\mathrm{P}_{0}$, apresentado no item anterior, pelos resultados apresentados na Tabela 9, foi possível determinar o esforço efetivo final em cada seção da estrutura, que podem ser consultados na Tabela 9 . O esforço efetivo final foi então comparado com os limites de cada seção, como pode ser visto na Figura 9. Embora os esforços efetivos tenham se 
aproximado dos valores mínimos para as seções centrais, os mesmos não foram ultrapassados, de modo que não há necessidade de serem alterados. Na seção 6, a mais crítica, a folga entre o esforço efetivo e o esforço mínimo necessário foi de 4,957 N, enquanto que nas demais seções essa folga apenas aumentou.

Figura 9 - Verificação do esforço de protensão após as perdas progressivas (em Newtons).

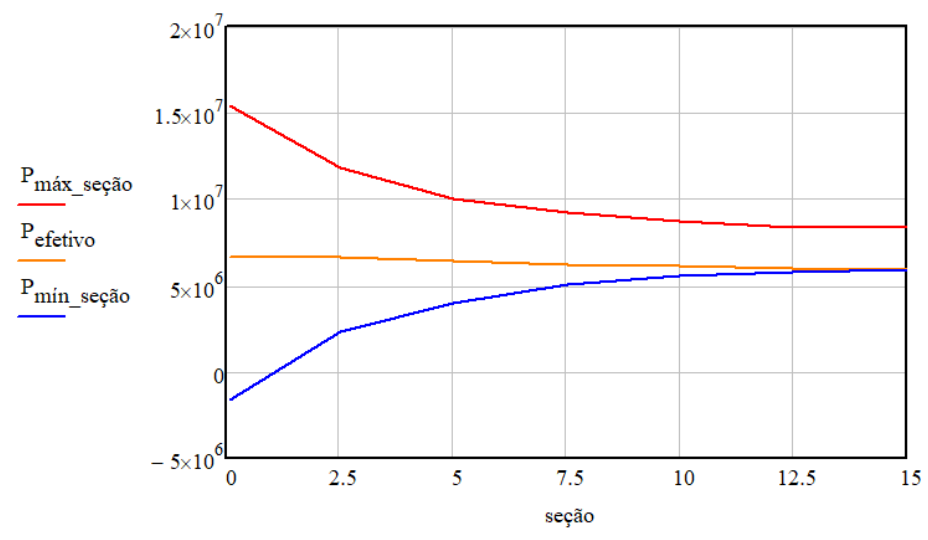

Fonte: Autores (2019).

\subsection{Dimensionamento ao Cisalhamento}

Os coeficientes utilizados para o dimensionamento foram $\gamma_{\mathrm{g}}=1,35$ para as cargas permanentes e $\gamma_{\mathrm{q}}=1,50$ para as cargas variáveis, pois ambos apresentam situações desfavoráveis para a combinação. Já no que diz respeito a parcela vertical da força de protensão utilizou-se o coeficiente $\gamma_{p}=0,90$ pois essa componente é favorável a diminuição do esforço total. Na Tabela 10 estão apresentados os resultados do cálculo dos esforços cortantes.

Na segunda coluna da Tabela 10 encontram-se os valores de cálculo considerando apenas as cargas permanentes e variáveis atuando, enquanto que na terceira coluna é feita a consideração da redução causada pela força de protensão. Na última coluna da tabela está destacado o quanto do esforço foi reduzido devido a protensão. Os valores são bastantes significativos pois acarretarão numa menor utilização de área de aço.

Tabela 10 - Combinações dos esforços cortantes.

\begin{tabular}{|c|c|c|c|c|c|}
\hline SEÇÃO & VS do $(k N)$ & $V_{d}(k N)$ & Redução do esforço $(\mathrm{kN})$ & Asw_calc $\left(\mathrm{cm}^{2} / \mathbf{m}\right)$ & Espaçamento (cm) \\
\hline $\mathrm{S} 0-\mathrm{S} 1$ & 1.609 & 1.130 & 479 & 9,375 & 16 \\
\hline $\mathrm{S} 1-\mathrm{S} 2$ & 1.359 & 961 & 397 & 6,794 & 20 \\
\hline $\mathrm{S} 2-\mathrm{S} 3$ & 1.269 & 958 & 310 & 6,828 & 20 \\
\hline $\mathrm{S} 3-\mathrm{S} 4$ & 914 & 687 & 226 & 3,21 & 33 \\
\hline $\mathrm{S} 4-\mathrm{S} 5$ & 698 & 552 & 146 & 3,21 & 33 \\
\hline S5 - S6 & 488 & 416 & 72 & 3,21 & 33 \\
\hline
\end{tabular}

Fonte: Autores (2019).

Para poder garantir a utilização dessa redução no dimensionamento a verificação de cisalhamento precisa ser respeitada. Para efetuar seu cálculo, considerou-se que a área de aço atuando na viga é igual a área mínima. Assim, o valor encontrado foi o seguinte:

$$
A_{p} f_{p y d}+A_{s} f_{y d}=10.250 \mathrm{kN}
$$


que, ao ser comparado com os valores da Tabela 10, percebe-se que está maior do que todos, garantindo o atendimento da restrição normativa. Utilizando o modelo de cálculo I da ABNT NBR 6118 (2014) e considerando estribos de 10 mm de diâmetro, efetuou-se o dimensionamento e os resultados podem ser observados na Tabela 10.

\subsection{Verificação do ELU de Fadiga}

Para se determinar as tensões máximas e mínimas que estão agindo em cada seção de controle da viga, levou-se em consideração o fato de que a única carga variável atuando sobre a estrutura é a passagem do trem-tipo. Dessa maneira, os momentos máximos foram determinados considerando todas as cargas permanentes atuando junto com o trem-tipo, enquanto que os momentos mínimos desconsideram a passagem do trem-tipo, restando apenas as parcelas permanentes. A ABNT NBR 6118 (2014) recomenda a utilização da combinação frequente de ações para determinar os momentos de fadiga.

Foi realizado o cálculo das tensões máximas e mínimas aplicando-se o resultado das combinações dos momentos e obteve-se a tensão no concreto em cada seção. Com isso, as tensões no aço foram obtidas através da correção pela relação entre os módulos de elasticidade dos materiais. A ABNT NBR 6118 (2014) recomenda utilizar $\alpha=10$ como relação para a análise em questão.

Dessa maneira, obteve-se os resultados presentes na Tabela 11, em que é possível notar que em nenhuma seção a variação de tensões ultrapassou o limite de $110 \mathrm{MPa}$ - preconizado pela ABNT NBR 6118 (2014) para o caso em apreço.

Tabela 11 - Resultados dos cálculos de fadiga.

\begin{tabular}{cccccc}
\hline SEÇÃo & $\mathbf{M}_{\text {máx }}(\mathbf{k N} . \mathbf{m})$ & $\mathbf{M}_{\text {mín }}(\mathbf{k N} . \mathbf{m})$ & $\boldsymbol{\sigma}_{\text {máx }}(\mathbf{M P a})$ & $\boldsymbol{\sigma}_{\text {mín }}(\mathbf{M P a})$ & $\boldsymbol{\Delta \sigma}_{\text {mín }}(\mathbf{M P a})$ \\
\hline S0 & 0 & 0 & 0 & 0 & 0 \\
S1 & 2005 & 1455 & 13,860 & 10,060 & 3,799 \\
S2 & 3574 & 2582 & 44,912 & 32,448 & 12,464 \\
S3 & 4901 & 3569 & 83,147 & 60,549 & 22,599 \\
S4 & 5809 & 4236 & 116,801 & 85,184 & 31,617 \\
S5 & 6369 & 4644 & 140,079 & 102,139 & 37,940 \\
S6 & 6568 & 4792 & 148,588 & 108,412 & 40,176 \\
\hline
\end{tabular}

Fonte: Autores (2019).

\subsection{Verificação do ELU de Flexão}

Para o presente trabalho, essa verificação será realizada com a Seção 6, pois, como visto anteriormente, essa é a seção com os maiores esforços de flexão. A metodologia utilizada para determinar o momento resistente numa seção da viga protendida é similar a utilizada para o concreto armado, porém, deve ser feita a consideração da aplicação do pré-alongamento nos cabos de aço, causado pela protensão. Assim, a deformação específica total do aço de protensão $\left(\varepsilon_{\text {total }}\right)$ é determinada pela soma da parcela referente ao equilíbrio da seção $\left(\varepsilon_{\text {eq }}\right)$ e o pré-alongamento causado pela protensão $\left(\varepsilon_{\text {ep }}\right)$, como ilustrado na Equação 16.

$$
\varepsilon_{\text {total }}=\varepsilon_{\text {eq }}+\varepsilon_{\text {ep }}
$$

De acordo com Cholfe (2018), a verificação do ELU para estruturas protendidas geralmente é realizada no domínio 3 de deformações, pois, por utilizar relativamente pequenas quantidades de aço, essas peças se encontram sub-armadas. A característica marcante desse domínio é que o aço encontra-se escoando. Dessa forma, para determinar o momento resistente, inicialmente utilizou-se o valor de cálculo da resistência referente ao escoamento do aço de protensão. Caso a deformação observada no aço não seja suficiente para haver o escoamento, a verificação deve ser realizada em um domínio diferente. 
A distância entre o centro do cabo mais externo ao centro de gravidade dos cabos é de $17 \mathrm{~cm}$, o que corresponde a exatamente 10\% da altura da viga, que é de 1,70 m, de modo que, de acordo com o item 17.2.4.1 da ABNT NBR 6118 (2014), é possível considerar o cabo equivalente na verificação do ELU. Caso a referida distância ultrapassasse 10\% da altura da viga, a norma supracitada exige que a análise seja feita para cada cabo individualmente.

Com o cabo equivalente, determinou-se o esforço total de tração a partir de sua área e de sua tensão de escoamento. Realizando o equilíbrio das forças, determinou-se a área de concreto comprimida equivalente e com esse valor determinou-se a posição da linha neutra da Seção 6. Como inicialmente considerou-se o domínio 3 de deformações, tem-se que a deformação máxima no concreto é de $0,35 \%$ e, com isso, foi possível determinar a deformação do aço referente ao equilíbrio ( $\varepsilon_{\text {eq }}$ ).

Após ter se realizado a verificação das deformações, observou-se que o aço de fato está escoando e que a estimativa inicial pôde ser seguida. Desse modo, determinou-se o centroide da área do concreto comprimida e calculou-se o momento resistente em relação ao posicionamento da armadura de protensão. $\mathrm{O}$ momento solicitante foi determinado utilizando os coeficientes (1,35 para as cargas permanentes e 1,50 para majorar as cargas variáveis) e os resultados obtidos foram: $\mathrm{M}_{\mathrm{Rd}}=$ $13200 \mathrm{kN} . \mathrm{m} \mathrm{e}_{\mathrm{sd}}=12040 \mathrm{kN} . \mathrm{m}$.

\subsection{Verificação do ELS de deformações excessivas}

Conforme o item 17.3.2.1.3 da ABNT NBR 6118 (2014), por se tratar de uma estrutura com armaduras ativas que foi projetada respeitando o limite de formação de fissuras, a rigidez a flexão equivalente para o cálculo da flecha pode ser considerada igual ao produto do módulo de elasticidade secante do concreto com a inércia da seção bruta. Assim, esses valores foram inseridos nas propriedades geométricas da viga no Ftool e obtiveram-se as flechas imediatas correspondentes a cada etapa de carregamento, valores esses que podem ser consultados na Tabela abaixo:

Tabela 12 - Flechas imediatas em cada etapa de carregamento.

\begin{tabular}{cc}
\hline ETAPA & FLECHA $(\mathbf{m m})$ \\
\hline 01 & 24,26 \\
02 & 15,31 \\
03 & 11,26 \\
04 & 17,28 \\
TOTAL & 68,11 \\
\hline
\end{tabular}

Fonte: Autores (2019).

Para calcular a flecha total, que inclui a parcela deferida no tempo, é necessário determinar o coeficiente de fluência do concreto, que foi apresentado no item 2.1.6.4. Para calculá-lo considerou-se o tempo inicial de projeto igual a 28 dias e o tempo final igual a 2000 dias, o que corresponde a um pouco mais de cinco anos. A flecha total $\left(a_{\text {total }}\right)$ foi calculada a partir da Equação 17:

$$
\mathrm{a}_{\text {total }}=\mathrm{a}_{\mathrm{i}}\left(1+\varphi\left(\mathrm{t}, \mathrm{t}_{0}\right)\right)
$$

na qual $a_{i}$ é a flecha imediata total e $\varphi\left(t, t_{0}\right)$ é o coeficiente de fluência. $O$ valor adquirido foi $a_{\text {total }}=20,30 \mathrm{~cm}$. Esse valor deve ser menor que o limite para aceitabilidade visual estabelecido na Tabela 13.3 na ABNT NBR 6118 (2014), dado pela Equação 18.

$$
\mathrm{a}_{\lim }=\frac{\mathrm{L}}{250}
$$


em que L corresponde ao vão livre da viga. A aplicação da Equação 18 com o vão de 30 metros resulta no limite $\mathrm{a}_{\text {lim }}=12 \mathrm{~cm}$. Como a flecha total resultou em um valor maior que o limite aceitável, optou-se por utilizar uma contraflecha (CF), que foi determinada utilizando a Equação 19.

$$
\mathrm{CF}=\mathrm{a}_{\text {total }}-\mathrm{a}_{\text {lim }}
$$

A contraflecha necessária resultou em $\mathrm{CF}=8,30 \mathrm{~cm}$, porém, por questões de facilidade de execução, foi adotado o valor $\mathrm{CF}=8,50 \mathrm{~cm}$, que respeita o limite máximo.

\subsection{Detalhamento}

\subsubsection{Ancoragens}

Como apresentado nos capítulos anteriores, é através das ancoragens que as forças dos cabos de protensão são transmitidas à estrutura de concreto. Por essa razão, é essencial o correto posicionamento e fixação das placas de apoio na forma do elemento estrutural. O projeto deve apresentar detalhadamente os nichos das ancoragens indicando suas dimensões e o ângulo de saída do cabo.

O catálogo Freyssinet Brasil (2018) apresenta as dimensões mínimas necessárias para o posicionamento de cada modelo de ancoragem disponível pela empresa, como pode ser observado na Figura 10. O primeiro número que aparece nos modelos da Tabela 13 diz respeito ao número de cordoalhas no cabo, e o segundo está relacionado ao diâmetro das cordoalhas, sendo 15 para as cordoalhas de diâmetro $15,2 \mathrm{~mm}$. Como para esse projeto, foi determinado a utilização de três cabos com 15 cordoalhas de com o diâmetro de $15,2 \mathrm{~mm}$, será utilizada a ancoragem de modelo $15 \mathrm{~K} 15$.

Deve-se atentar na Figura 10 principalmente para a distância C, que controla o afastamento do centro do cabo a lateral da seção transversal e a distância E, que diz respeito ao afastamento mínimo vertical entre os eixos dos cabos. Devido ao alargamento da seção no apoio e ao fato dos três cabos estarem posicionado verticalmente no mesmo plano, as demais dimensões são facilmente respeitadas.

Figura 10 - Representação das dimensões mínimas das ancoragens.

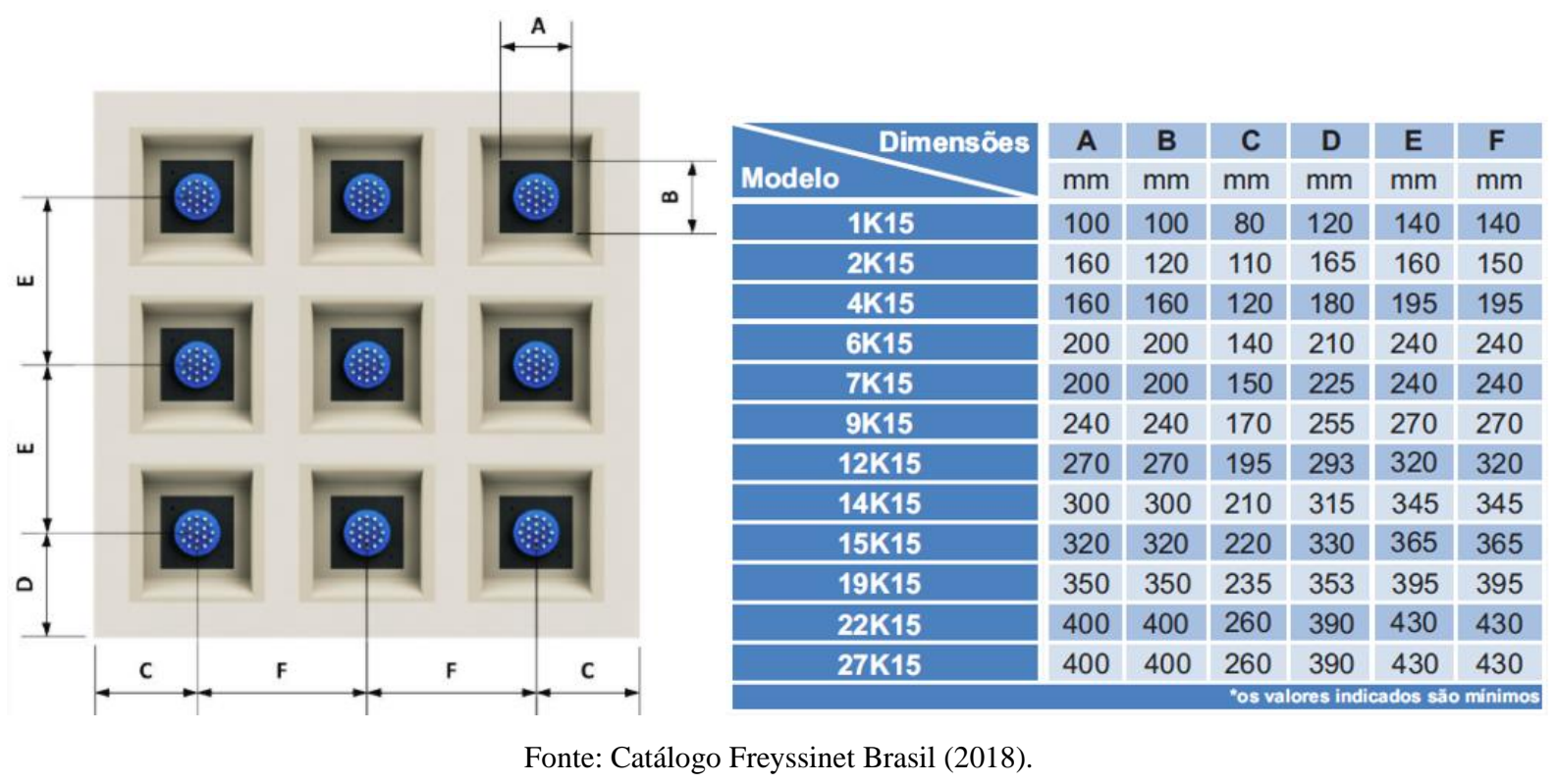




\subsubsection{Fretagens de Ancoragens}

As fretagens são armaduras posicionadas atrás das ancoragens com a finalidade de resistir aos esforços de tração que se originam do esforço local do cabo. Elas atuam para evitar a ruptura local do concreto devido as tensões locais muito elevadas. $\mathrm{O}$ catálogo Freyssinet Brasil (2018) apresenta ancoragens que já possuem a armadura de fretagem acoplada. Os modelos com armadura de fretagem tipo mola pode ser observado na Figura 11 e suas dimensões estão presentes na Tabela 13.

Figura 11 - Fretagem tipo mola.
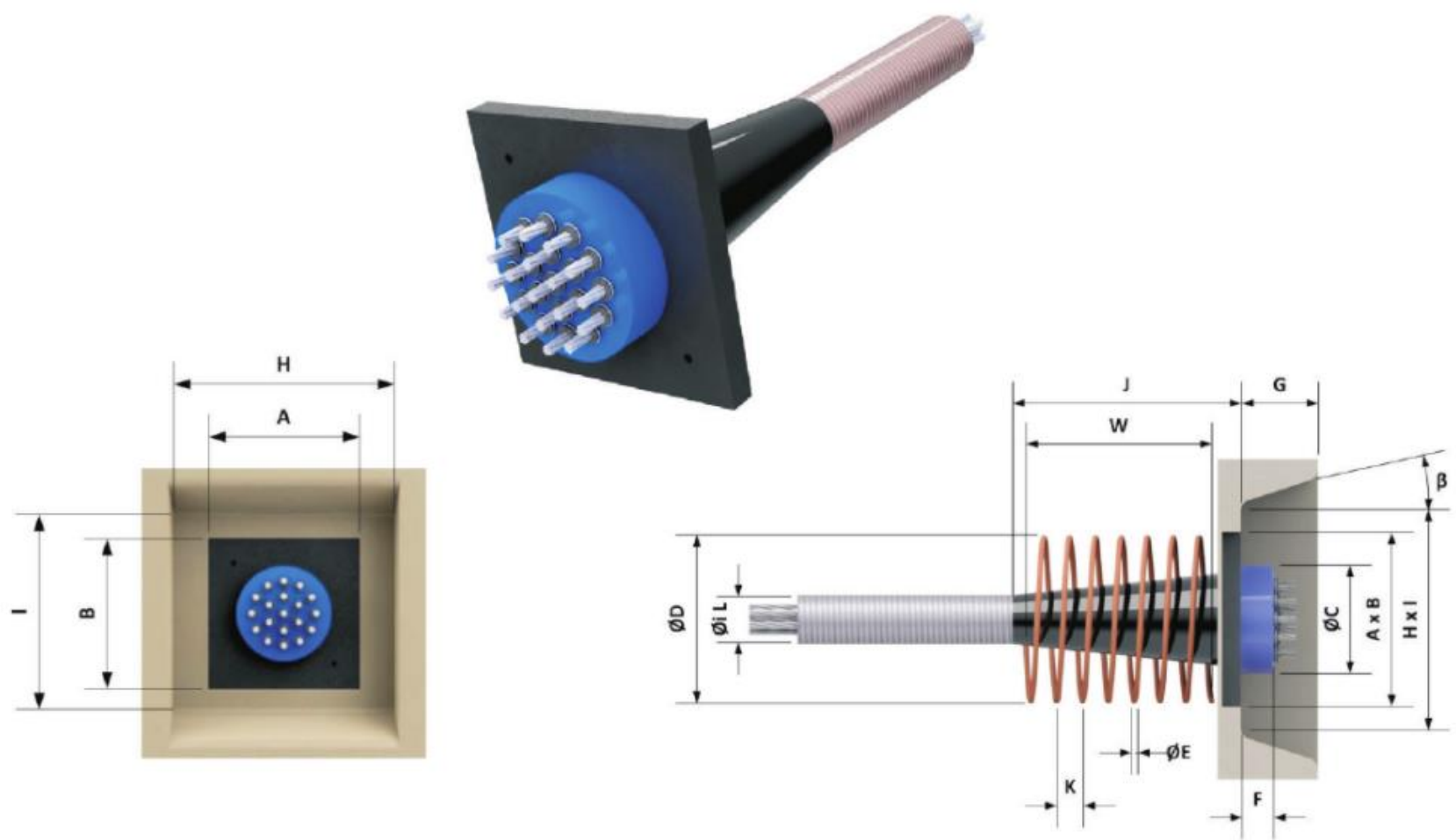

Fonte: Catálogo Freyssinet Brasil (2018).

Tabela 13 - Especificações da fretagem tipo mola.

\begin{tabular}{|c|c|c|c|c|c|c|c|c|c|c|c|c|c|c|}
\hline & & & & & & & & & & & \multicolumn{4}{|c|}{ Armadura de Fretagem - CA-50 } \\
\hline Dimensões & A & B & $\varnothing c$ & $\mathbf{F}$ & G & $\mathbf{H}$ & I & $\mathbf{J}$ & ØiL & $\beta$ & ØD & ØE & $\mathbf{w}$ & $\mathbf{K}$ \\
\hline Aodelo & $\mathrm{mm}$ & $\mathrm{mm}$ & $\mathrm{mm}$ & $\mathrm{mm}$ & $\mathrm{mm}$ & $\mathrm{mm}$ & $\mathrm{mm}$ & $\mathrm{mm}$ & $\mathrm{mm}$ & deg. & $\mathrm{mm}$ & $\mathrm{mm}$ & $\mathrm{mm}$ & $\mathrm{mm}$ \\
\hline $1 K 15$ & 100 & 100 & 51 & 55 & 80 & 120 & 120 & 120 & 30 & 10 & 115 & 8 & 155 & 50 \\
\hline $2 \mathrm{~K} 15$ & 160 & 120 & 90 & 55,5 & 80 & 180 & 140 & 98 & 35 & 10 & 170 & 8 & 170 & 50 \\
\hline $4 K 15$ & 160 & 160 & 114 & 55 & 130 & 180 & 180 & 180 & 45 & 10 & 170 & 10 & 250 & 50 \\
\hline 6K15 & 200 & 200 & 140 & 55 & 130 & 220 & 220 & 195 & 60 & 10 & 210 & 10 & 300 & 50 \\
\hline $7 K 15$ & 200 & 200 & 140 & 55 & 130 & 220 & 220 & 195 & 65 & 10 & 210 & 10 & 300 & 50 \\
\hline $9 K 15$ & 240 & 240 & 165 & 68,5 & 140 & 260 & 260 & 270 & 70 & 15 & 255 & 12 & 350 & 50 \\
\hline $12 \mathrm{~K} 15$ & 270 & 270 & 165 & 68,5 & 140 & 290 & 290 & 270 & 80 & 15 & 285 & 12 & 400 & 50 \\
\hline $14 K 15$ & 300 & 300 & 197 & 76 & 155 & 320 & 320 & 280 & 85 & 20 & 315 & 12 & 450 & 50 \\
\hline $15 K 15$ & 320 & 320 & 197 & 76 & 155 & 340 & 340 & 280 & 85 & 20 & 335 & 12 & 450 & 50 \\
\hline $19 K 15$ & 350 & 350 & 197 & 76 & 155 & 370 & 370 & 280 & 95 & 20 & 365 & 16 & 510 & 60 \\
\hline $22 \mathrm{~K} 15$ & 400 & 400 & 254 & 80 & 160 & 420 & 420 & 475 & 100 & 20 & 420 & 20 & 595 & 70 \\
\hline $27 K 15$ & 400 & 400 & 254 & 80 & 160 & 420 & 420 & 475 & 110 & 20 & 420 & 20 & 665 & 70 \\
\hline
\end{tabular}

Fonte: Adaptado do Catálogo Freyssinet Brasil (2018).

\subsubsection{Configuração Final}

Respeitando os limites apresentados no item anterior, foram então posicionadas as ancoragens nas extremidades das vigas e a partir delas, determinaram-se os traçados definitivos de cada um dos três cabos. Na Figura 
12, está presente a vista de uma das laterais da longarina com destaque para o distanciamento entre as ancoragens. A seção apresentada na Figura 12 diz respeito a seção do apoio que possui o alargamento da alma para alocar melhor as ancoragens e melhorar a resistência aos esforços cortantes.

Na Figura 12 expõe-se um corte longitudinal dos nichos de ancoragem, de modo que se pode observar as diferentes angulações de cada cabo.

Ao serem aplicadas corretamente, as angulações da Figura 12 garantem a perpendicularidade entre a saída do cabo e a face do concreto, o que evita o surgimento de tensões extras na região. Por fim, a Fonte: Autores (2019).

Tabela 14 apresenta a elevação de cada cabo em função das seções de controle.

Figura 12 - Distribuição das ancoragens na seção do apoio.
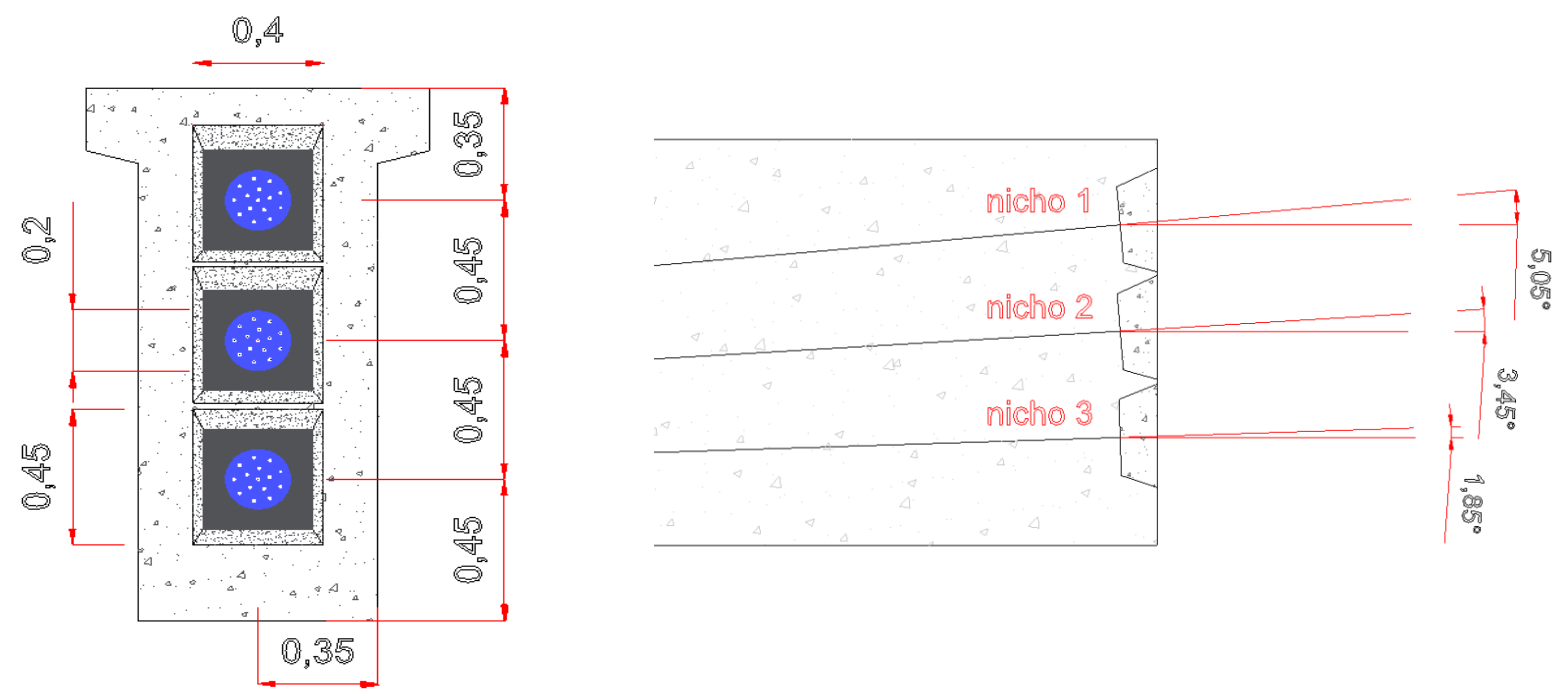

Fonte: Autores (2019).

Tabela 14 - Elevações de cada cabo nas seções de controle em $\mathrm{cm}$.

\begin{tabular}{|c|c|c|c|c|c|c|c|}
\hline CABO & SEÇÃO 00 & SEÇÃO 01 & SEÇÃO 02 & SEÇÃO 03 & SEÇÃO 04 & SEÇÃO 05 & SEÇÃ̃ 06 \\
\hline 01 & 135 & 114 & 93 & 75 & 60 & 51 & 47 \\
\hline 02 & 90 & 76 & 62 & 49 & 39 & 33 & 30 \\
\hline 03 & 45 & 38 & 30 & 23 & 18 & 14 & 13 \\
\hline
\end{tabular}

Fonte: Autores (2019).

\section{Considerações Finais}

Este trabalhou proporcionou o estudo da protensão em peças de concreto e permitiu a aplicação dos conceitos abordados em um caso prático real na cidade de Caruaru-PE. Realizou-se o dimensionamento da longarina mais solicitada, sendo essa a da extremidade do tabuleiro.

Foi possível observar e mensurar todas as perdas de protensão que ocorrem ao longo das seções de controle e também ao longo do tempo. Perdas essas que corresponderam a cerca de $30 \%$ do esforço inicial aplicado. Um valor bastante significativo que caso não seja estimado corretamente, a estrutura pode vir a romper pelo fato de o esforço ter sido reduzido demasiadamente.

A análise do estado limite último permitiu identificar que a estrutura não necessita de armadura complementar, de modo que apenas os três cabos de protensão foram suficientes para resistir ao momento solicitante. No que diz respeito a fadiga, observou-se pequenas variações de tensões, que se encontram bastante abaixo do limite estipulado pela ABNT NBR 6118 (2014), 
diferentemente do que é observado em pontes de concreto armado, nas quais as variações de tensão comumente ultrapassam o limite da norma.

No que diz respeito ao estado limite de deformações excessivas, observou-se flechas relativamente pequenas para uma viga com $30 \mathrm{~m}$ de vão. Isso se deve ao fato de que a protensão limitada possibilita a utilização da inércia bruta do concreto para o cálculo das flechas, pois como o limite de formação de fissuras é respeitado, as seções do concreto encontram-se sem aberturas.

Trabalhos acadêmicos futuros podem contribuir para disseminar ainda mais a utilização da protensão, com intuito de explorar as vantagens que esse sistema oferece. Dessa maneira, são apresentadas a seguir algumas sugestões para futuras pesquisas:

- Realizar o dimensionamento dos outros elementos da ponte, como lajes e pilares, utilizando a protensão.

- $\quad$ Considerar parcelas das lajes como mesa colaborante das longarinas protendidas;

- $\quad$ Comparação de custo entre a estrutura em concreto armado e a estrutura protendida;

- $\quad$ Aplicar a protensão em outros tipos diferentes de estrutura.

\section{Agradecimentos}

Os autores agradecem à Fundação de Amparo à Ciência e Tecnologia de Pernambuco (FACEPE), à Pró-Reitoria de Pós-Graduação (PROPG) e à Coordenação de Aperfeiçoamento de Pessoal de Nível Superior (CAPES), pelo financiamento das pesquisas desenvolvidas no Programa de Pós-Graduação em Engenharia Civil e Ambiental (PPGECAM) da Universidade Federal de Pernambuco (UFPE) no Campus Caruaru.

\section{Referências}

ABNT. (2003) - Associação Brasileira de Normas Técnicas. NBR 7187:2003 - Projeto de pontes de concreto armado e de concreto protendido - Procedimento. ABNT. (2003) - Associação Brasileira de Normas Técnicas. NBR 8681:2003 - Ações e segurança nas estruturas - Procedimento.

ABNT. (2008) - Associação Brasileira de Normas Técnicas. NBR 7483:2008 - Cordoalha de aço para estruturas de concreto protendido - Especificação.

ABNT. (2013) - Associação Brasileira de Normas Técnicas. NBR 7188:2013 - Carga móvel rodoviária de pedestres em pontes, viadutos, passarelas e outras estruturas.

ABNT. (2014) - Associação Brasileira de Normas Técnicas. NBR 6118:2014 - Projeto de estruturas de concreto - procedimento.

Alcalá, J., Gonzalez-Vidoza, F., Martí, J. V. \& Yepes, V. (2018). Embodied Energy Optimization of Prestressed Concrete Slab Bridge Decks. Technologies, 43 (6).

Bonopera, M., Chang, K. C., Chen, C. C., Sung, Y. C. \& Tullini, N. (2019). Experimental study on the fundamental frequency of prestressed concrete bridge beams with parabolic unbonded tendons. Journal of Sound and Vibration, 455, 150-160.

Catálogo Freyssinet Brasil. (2018). Sistema Freyssinet para protensão e estais.

Cholfe, L. (2018). Concreto protendido: teoria e prática. São Paulo: Oficina de Textos, 2 ed.

Flick, U. (2009). Desenho da pesquisa qualitativa. Artmed.

García-Segura, T. \& Yepes, V. (2016). Multiobjective optimization of post-tensioned concrete box-girder road bridges considering cost, CO2 emissions, and safety. Engineering Structures, 125, 325-336.

García-Segura, T., Yepes, V. \& Frangopol, D. M. (2017). Multi-objective design of post-tensioned concrete road bridges using artificial neural networks. Structural and Multidisciplinary Optimization, 56, 139-150.

Gonzalez-Vidosa, F., Gonzalez, J. A. \& Ferrer, F. N. (2020). On the structural design of characteristic decks for three-span postensioned road flyovers. WIT Transactions on The Built Environment, 196, $169-180$.

Hemalatha, K., James, C., Natrayan, L. \& Swamynadh, V. (2021). Analysis of RCC T-beam and prestressed concrete box girder bridges super structure under different span conditions. Materials Today Proceedings, 37 (2), 1507-1516.

Malhotra, N., Rocha, I., \& Laudisio, M.C. (2005). Introdução à Pesquisa de Marketing. Pearson Prentice Hall. 
Research, Society and Development, v. 11, n. 3, e36711326752, 2022

(CC BY 4.0) | ISSN 2525-3409 | DOI: http://dx.doi.org/10.33448/rsd-v11i3.26752

Martí, J. V., García-Segura, T. \& Yepes, V. (2016). Structural design of precast-prestressed concrete U-beam road bridges based on embodied energy. Journal of Cleaner Production, 120, 231-240.

Martí, J. V., Gonzalez-Vidosa, F., Yepes, V. \& Alcalá, J. (2013). Design of prestressed concrete precast road bridges with hybrid simulated annealing. Engineering Structures, 48, 342-352.

Nour, N. A., Vié, D., Chateauneufa, A., Amziane, S. \& Kallassy, A. (2021). Dimensioning of partially prestressed concrete beams, optimization of T-shaped section with heels. Engineering Structures, 235, 112054.

Penadés-Plà, V., García-Segura, T., Martí, J. V. \& Yepes, V. (2018). An Optimization-LCA of a Prestressed Concrete Precast Bridge. Sustainability, $10,685$.

Penadés-Plà, V., Martí, J. V., García-Segura, T. \& Yepes, V. (2017). Life-cycle assessment: A comparison between two optimal post-tensioned concrete boxgirder road bridges. Sustainability, 9, 1864.

Pereira, A. S., Shitsuka, D. M., Parreira, F. J. \& Shitsuka, R. (2018). Metodologia da pesquisa científica. UFSM.

Pfeil, W. (1984). Concreto protendido, 1: Introdução. Rio de Janeiro: LTC - Livros Técnicos e Científicos Editora S.A.

Silva, N. G. da, Souza, O. L. de C. \& Campos, C. M. de O. (2020). Análise de confiabilidade em vigas de concreto protendido com cabos não aderentes em conformidade com a NBR 6118-2014: estudo paramétrico para razões de carga e resistência a compressão do concreto. Research, Society and Development, 9 (10), e7239109172.

Spernau, W. (2012). Apostila de Pontes. Universidade Federal de Santa Catarina. Centro Tecnológico, Departamento de Engenharia Civil.

Yepes, V., Martí, J. V. \& García-Segura, T. (2015). Cost and CO2 emission optimization of precast-prestressed concrete U-beam road bridges by a hybrid glowworm swarm algorithm. Automation in Construction, 49, 123-134.

Yepes, V., Martí, J. V. \& García-Segura, T. (2017). Design optimization of precast-prestressed concrete road bridges with steel fiber-reinforcement by a hybrid evolutionary algorithm. International Journal of Computational Methods and Experimental Measurements, 5 (2), 179-189. 